\section{NOTA TÉCNICA}

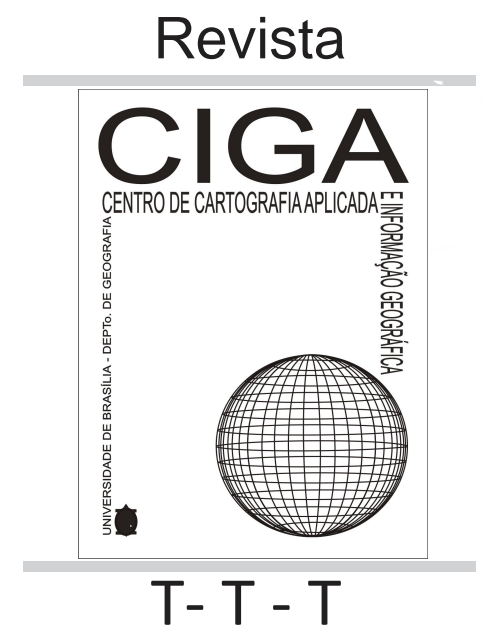

Revista Eletrônica: Tempo - Técnica - Território, V.10, N.2 (2019), 100-119 ISSN: 2177-4366

\section{OS MAPAS DO PROJETO CARTO CINEMA II - 2020}

\section{Rafael Sanzio Araújo dos Anjos Gustavo Silveira Tolentino}

p. $100-119$

Como citar este artigo:

Ajos, R, S, A. Tolentino, G, S.

OS MAPAS DO PROJETO CARTO CINEMA II - 2020 Revista

Eletrônica: Tempo - Técnica - Território, v.10, n.2 (2019),p.100-119

ISSN: $2177-4366$

Disponível em: http://periodicos.unb.br/index.php/ciga/

Este obra está licenciado com uma Licença Creative Commons Atribuição - Não Comercial 4.0 Internacional. 


\title{
OS MAPAS DO PROJETO CARTO CINEMA II - 2020
}

\author{
NOTA TÉCNICA
}

Rafael Sanzio Araújo dos Anjos

E-mail:quilombo.sanzio@gmail.com

Site: www.projetogeoafrobrasil.com

Geógrafo, Doutor em Informações Espaciais Pós-Doutorado Cartografia Étnica. Prof.

Titular da Universidade de Brasília / Diretor do Centro de Cartografia Aplicada e Informação Geográfica do Depto. de Geografia - UnB

\author{
Gustavo Silveira Tolentino \\ Geógrafo, mestrando em Geografia pelo Programa de Pós-Graduação em Geografia da \\ Universidade de Brasília (UnB). \\ E-mail: gustavosilveira.t@gmail.com
}




\section{PROCEDIMENTOS, MATERIAIS E MÉTODO}

O CIGA - UnB em parceria com o Instituto Baobás ficaram responsáveis pela produção da cartografia temática do Projeto Carto Cinema II (FAC-GDF-2020), que se constituiu basicamente na espacialização e representação de cada ponto de tomada de cinema sobre o território do Distrito Federal. A produção cartográfica se dividiu em quatro etapas, sendo elas: $1^{\circ}$. A sistematização da base de dados do Projeto; $2^{\circ}$. O mapeamento preliminar dos pontos; $3^{\circ}$. A escolha e criação da simbologia e $4^{\circ}$. A organização da legenda e do layout dos documentos cartográficos. Foram utilizados os software do Google Earth, Quantum Gis (QGIS) e Corel Draw no processo de elaboração dos produtos cartográficos. A primeira planilha de dados com 118 pontos foi enviada no início de março 2020 . As informações contidas constavam apenas com as coordenadas geográficas, os nomes de cada tomada, ano de algumas filmagens e suas categorias de tomadas. A Figura 01 apresenta a primeira planilha que deu início do desenvolvimento dos produtos cartográficos. No meado deste mês recebemos a segunda planilha de dados com 179 e continham novas informações como o nome dos cineastas e as categorias de cada tomada. No início de abril foi encaminhada a planilha final, que posteriormente passaria por algumas correções. De 179 pontos passamos a ter 273. A planilha final encontra-se em anexo (Anexo I) e apresenta o total de todos os pontos que foram georreferenciados. A espacialização dos pontos ocorreu através da localização das coordenadas geográficas por meio do software Google Earth, como apresentado na Figura 02. Os pontos das tomadas foram categorizados, a princípio, de acordo com os cineastas e posteriormente conferidas de acordo com as informações contidas na planilha. Os pontos que apresentavam problemas de localização com as coordenadas errôneas, foram corrigidos. 
pontos de locacoes de filmes 1985 a 2005 is 60

Arquivo Editar Ver Inserir Formatar Dados Ferramentas Complementos Ajuda Aúltima ediçẵo foi feita há alguns segundos por anônimo

目

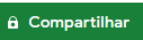

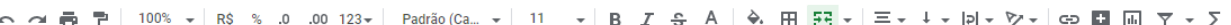

Listado de loç̧̃̃es de filmes rodados em Brasilia 1985-2005

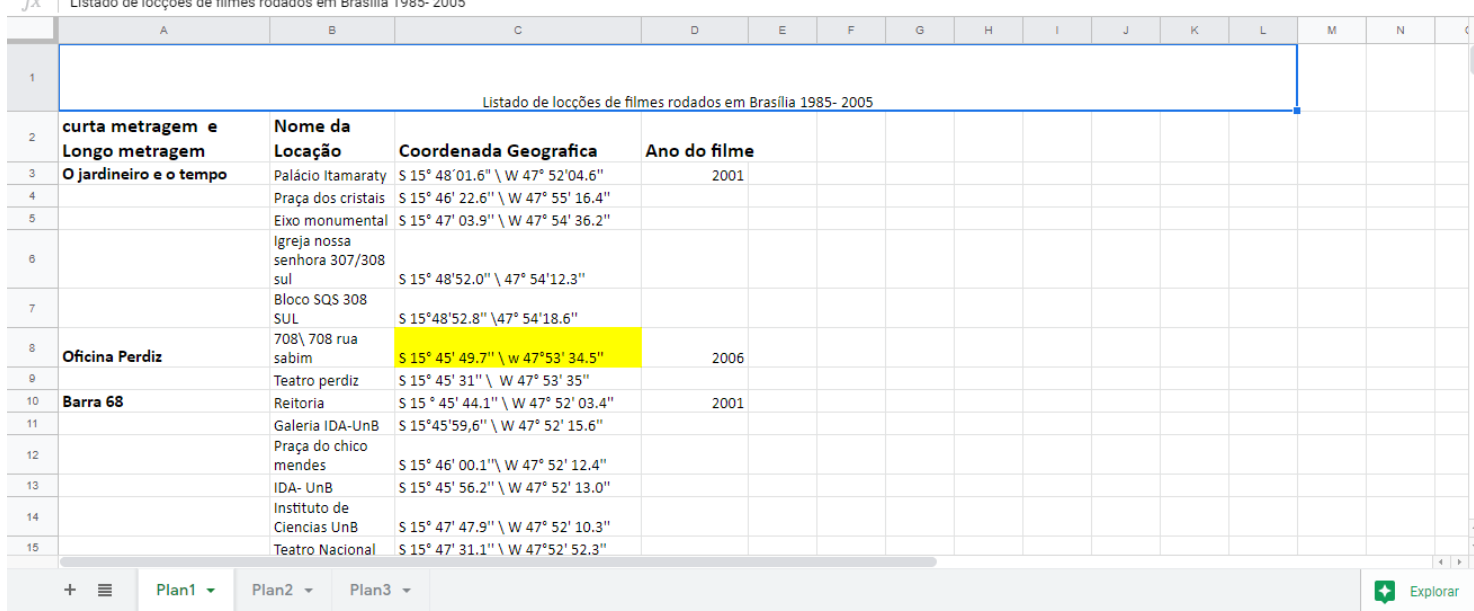

Figura 01: 1a planilha enviada pela equipe ITS no dia 4 de março de 2020. 0 arquivo recebido deu início a produção dos produtos cartográficos.

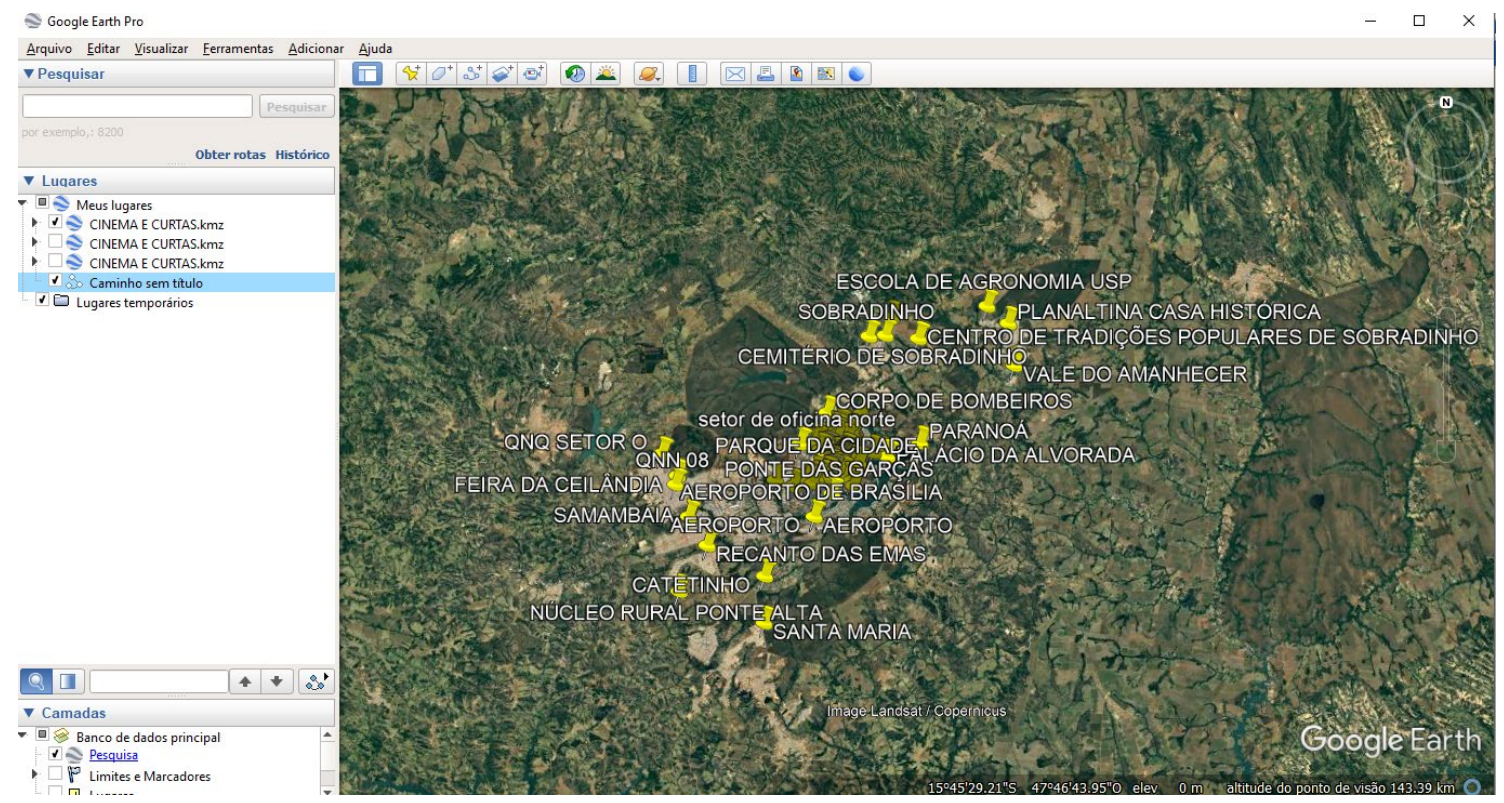

Figura 02 Espacialização dos pontos contidos na tabela. Fonte: Google Earth.

A Figura 03 apresenta a base cartográfica utilizada do Distrito Federal. Ou seja, um mosaico de ortofotos digitais realizada pela Companhia de Planejamento do Distrito Federal (CODEPLAN).

A elaboração e criação dos símbolos das tomadas de cinemas buscou representações gráficas que expressassem os pontos mapeados, ou seja, tomadas de filmagens de documentário, de curta e de longa metragem. A Figura 04 apresenta os ícones definidos para o desenvolvimento dos produtos cartográficos. 


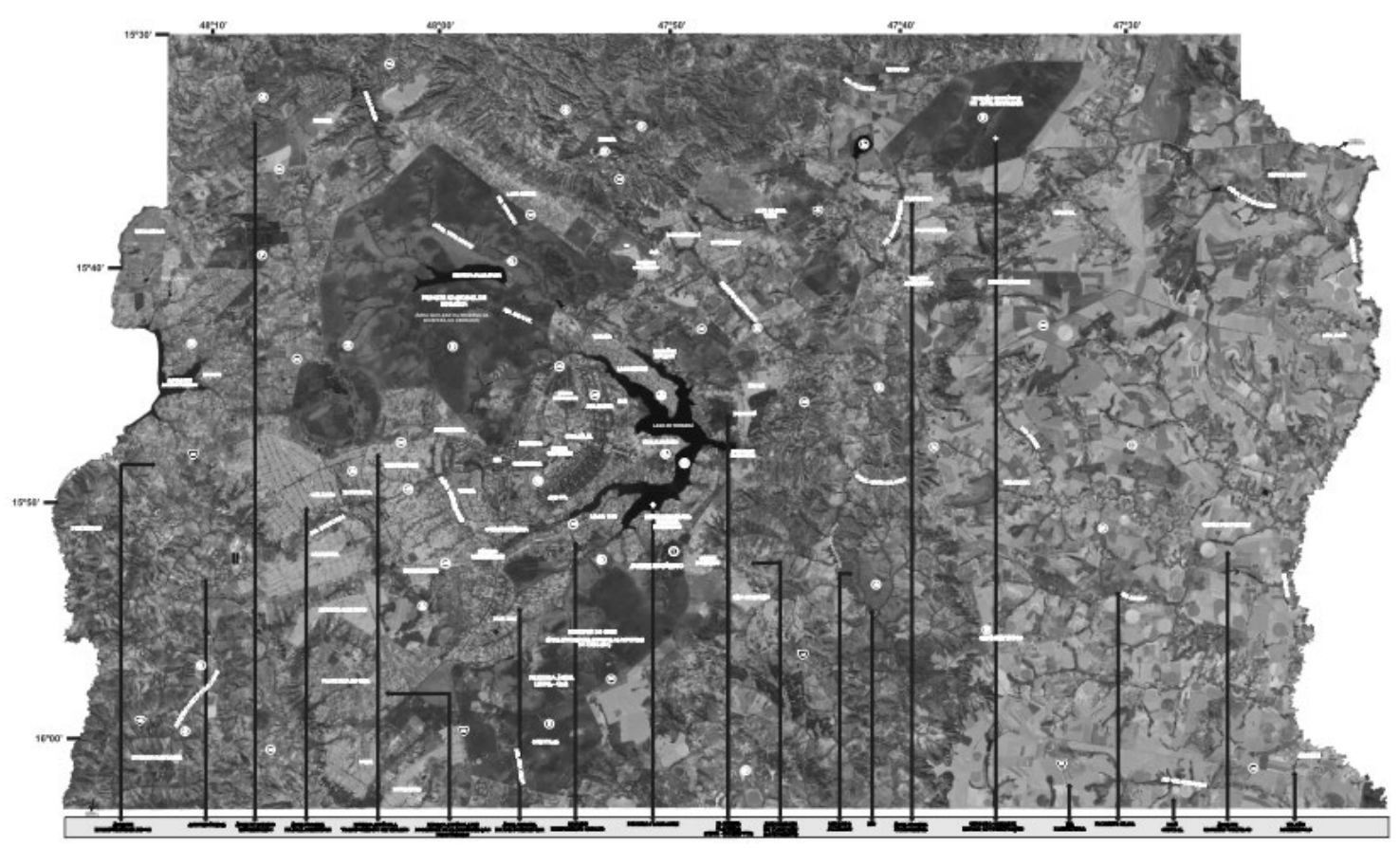

Figura 03 Mosaico de ortofotos digitais do Distrito Federal. 2017. Fonte: CODEPLAN-GDF

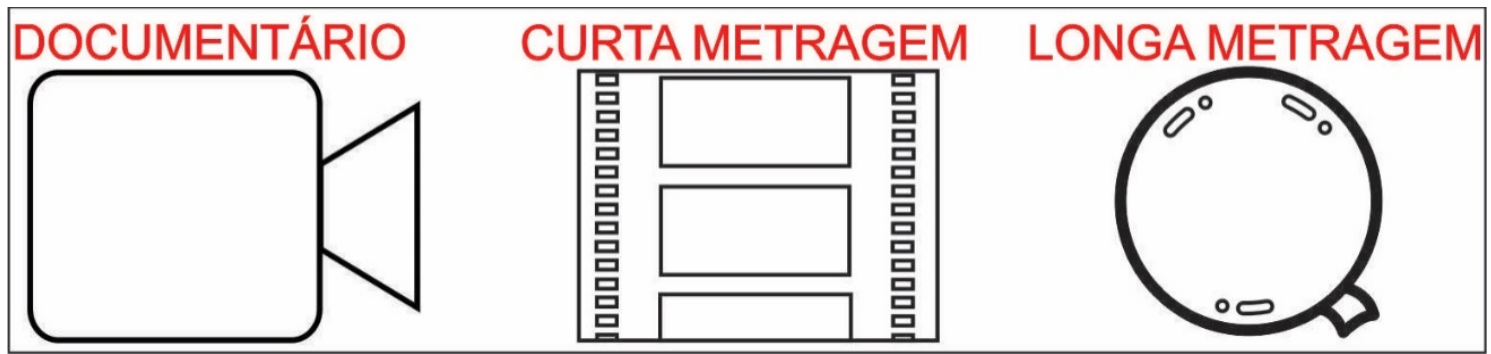

Figura 04. Simbologia das tomadas de documentário, curta e longa metragem. Fonte: Flaticon, Freepik 2020.

\section{PRODUÇÃO DOS MAPAS DE TOMADAS DE DOCUMENTÁRIO, CURTA E LONGA METRAGEM}

Foram elaborados três mapas de acordo com as tomadas de documentário, de curta e de longa metragem. Tomamos como premissa uma produção cartográfica que valorizasse a a temática trada, assim como informasse a sua distribuição espacial e possibilitasse o detalhamento possível a partir de encartes (recurso cartográfico para ampliação da informação espacial). Elaboramos uma cartografia quantitativa, onde a simbologia está associada a um número com tamanhos diferentes e, qualitativa, com a distribuição em categorias de uma informação espacial, no caso tomadas de cinema 
(documentário, curta e longa metragem). Junto com a legenda foi inserido um quadro com a numeração e nome dos pontos, assim como o ano de realização da tomada de cinema. As Figuras 05, 06 e 07 mostra os documentos cartográficos construídos.

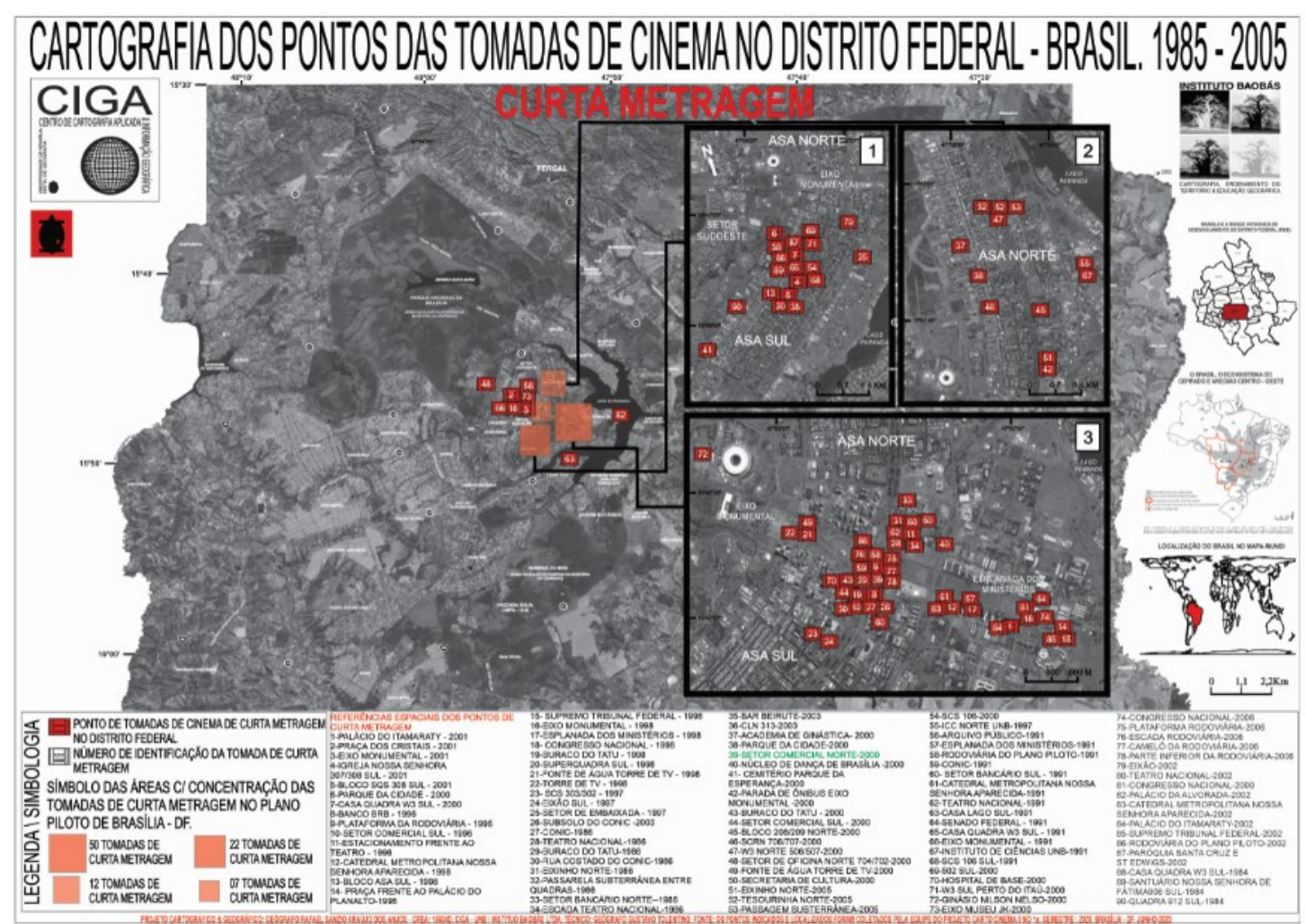

Figura 05 Mapa Temático dos Pontos das Tomadas de Cinema no DF - Brasil. 1985 - 2005. Curta Metragem

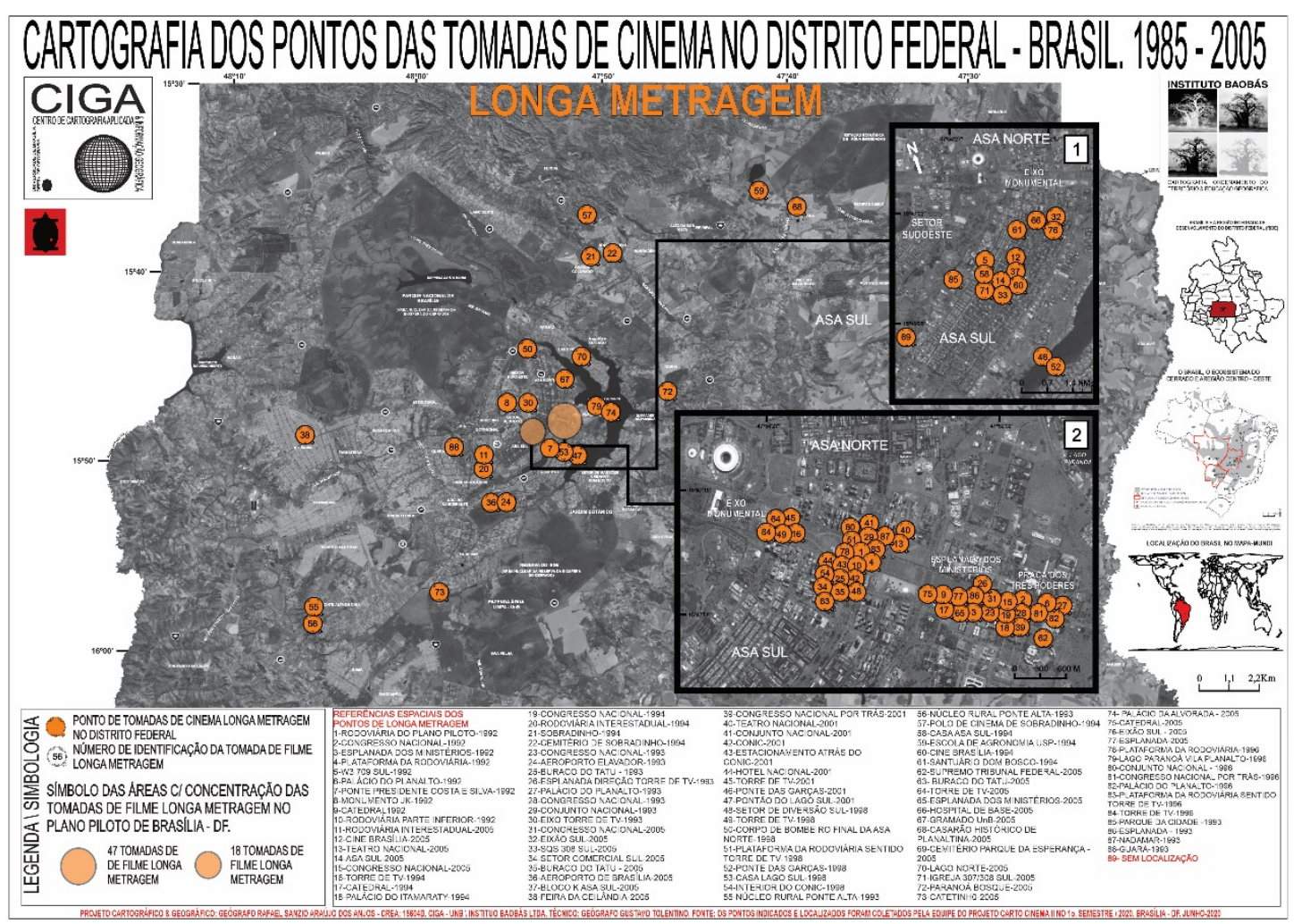

Figura 06 Mapa Temático dos Pontos das Tomadas de Cinema no DF - Brasil. 1985 - 2005. Longa Metragem 


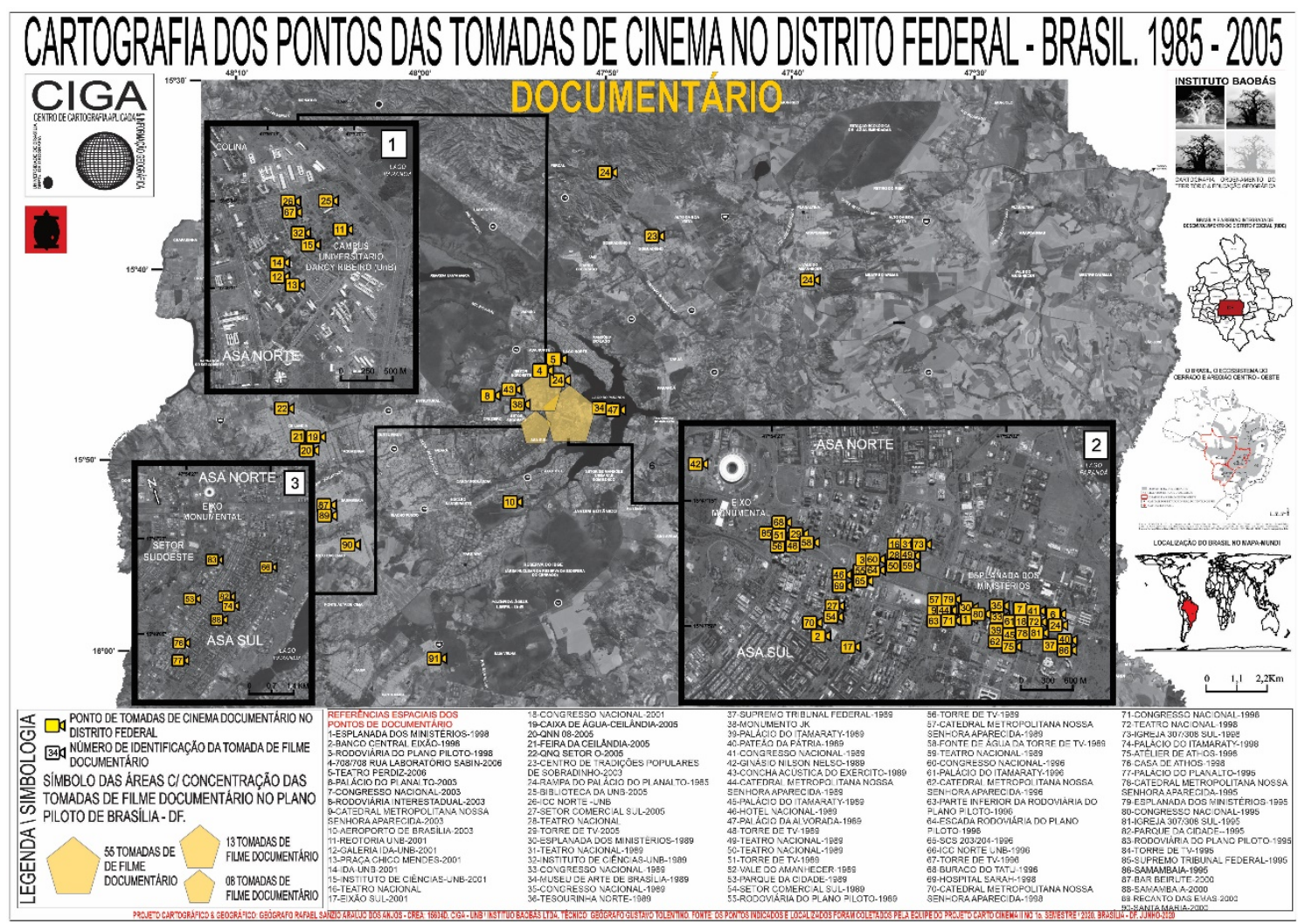

Figura 07 Mapa Temático dos Pontos das Tomadas de Cinema no DF - Brasil. 1985 - 2005. Documentário

\section{MAPA GERAL DOS PONTOS DE DOCUMENTÁRIO, CURTA E LONGA METRAGEM}

O mapa final com todos os dados sistematizados caracteriza-se por representar graficamente todas as tomadas as tomadas de cinema nas categorias de documentário, curta e longa metragem. A Figura 08 mostra o processo espacial de agrupamento e superposição dos dados dos mapas temáticos e o produto cartográfico síntese está representado na Figura 09. As cores de cada tomadas seguem o padrão dos símbolos específicos no mapa, sendo amarelo para documentário, vermelho para curta metragem e laranja para longa metragem e a legenda agregou os três temas. As referências espaciais com os números e nomes dos pontos ficaram nas laterais do documento, indicando as tomadas de acordo com o número dos pontos. $\mathrm{Na}$ área de representação do mapa temático temos três encartes cartográficos de áreas de grande concentração de dados espaciais. 


\section{CARTOGRAFIA DO PROJETO CARTO CINEMA II - DISTRITO FEDERAL ESTRUTURA DA SUPERPOSIÇÃO ESPACIAL DOS MAPAS TEMÁTICOS}

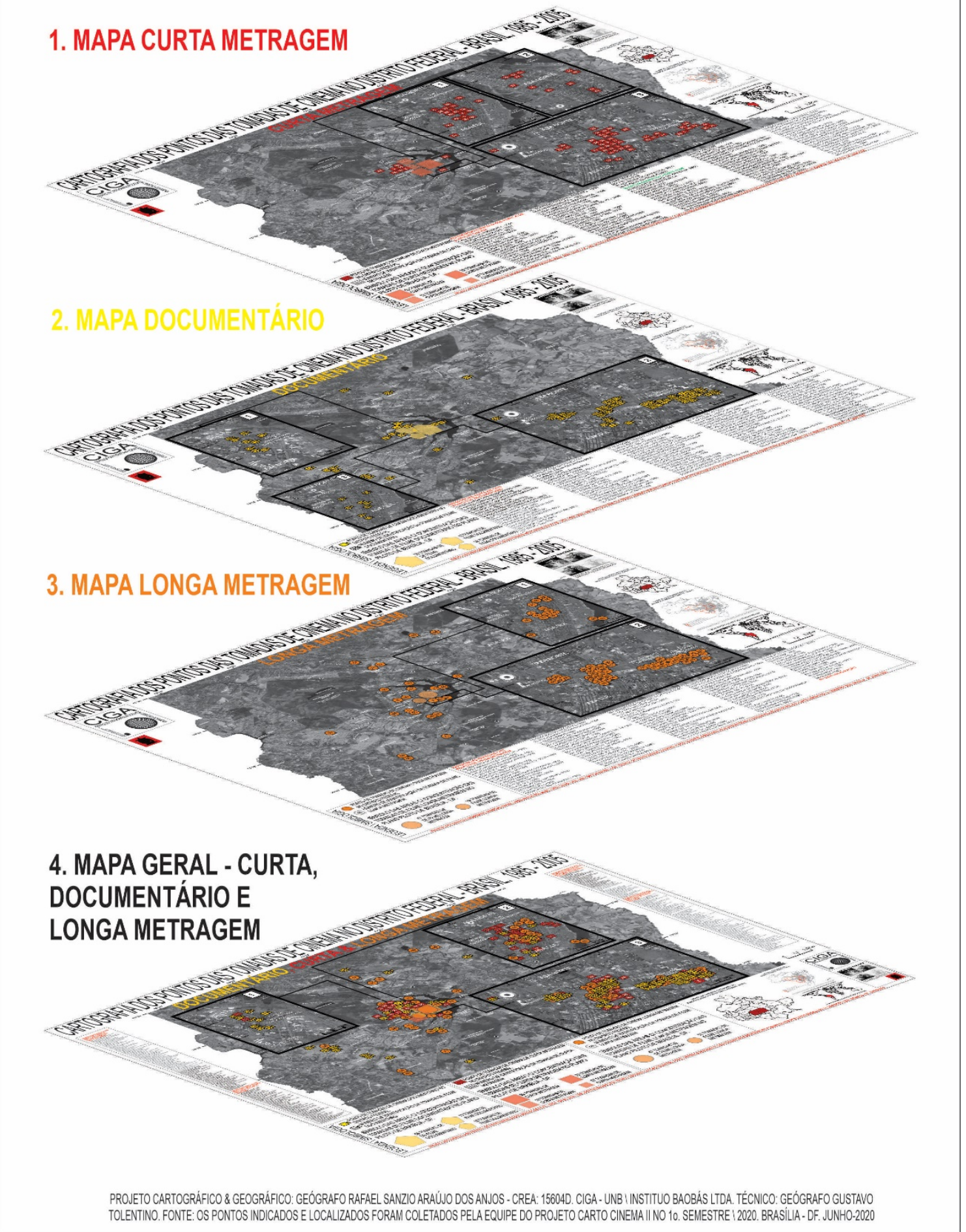

Figura 08 Agrupamento de dados dos mapas de curta metragem, de documentário e de longa metragem. Essas informações deram fundamento ao mapa final. 


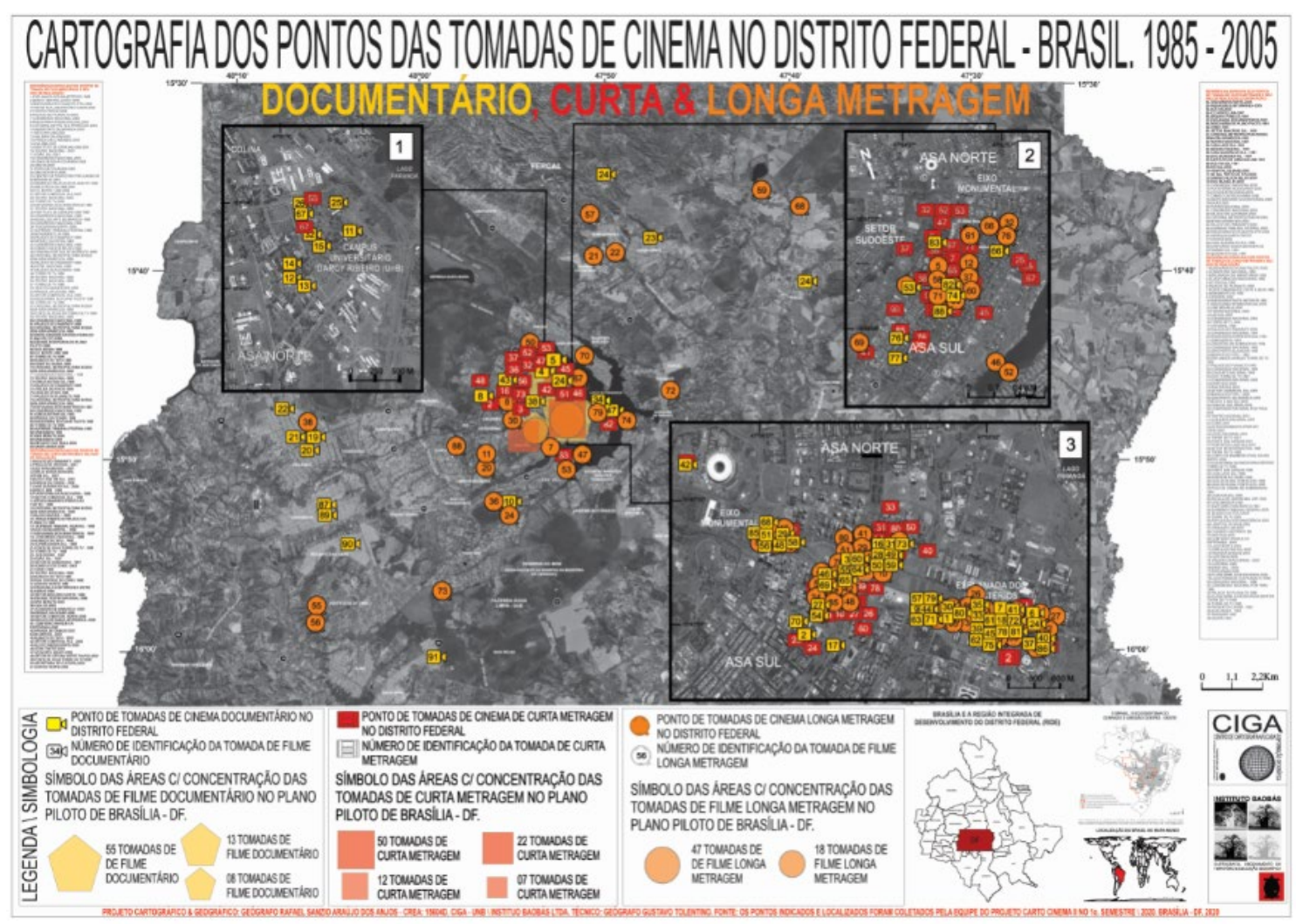

Figura 09 Mapa Temático dos Pontos das Tomadas de Cinema no DF - Brasil. 1985 - 2005. Documentário, Curta e Longa Metragem 


\section{ANEXO I - PLANILHA FINAL}

Listado de locções de filmes rodados em Brasília 1985- 2005

\section{curta metragem e} Longo metragem O jardineiro do tempo

Por longos dias

Barra 68

Suco de Beterraba

De Esperança e

Esperança

Oficina Perdiz

IDA- UnB
Galeria IDA-UnB

Praça do chico mendes

Ano do

Nome da Locação filme

Palácio Itamaraty

Praça dos cristais

Eixo monumental

Igreja nossa senhora

$307 / 308$ sul

Bloco SQS 308 SUL

Esplanada dos ministérios 1998

Banco central eixão

monumental

Rodoviária

$708 \backslash 708$ rua laboratorio

Sabin

Teatro perdiz

Parque da cidade

Casa quadra w3 sul

Palácio Planalto

Congresso

Rodoviária interestadual

Catedral

Aeroporto de Brasília

Reitoria

Praça do chico mendes

2001

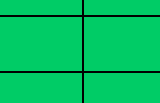

metragem

Curta

metragem

Curta

metragem

\section{Curta}

metragem

Curta

metragem

D

Documentario

Documentario

2006

\begin{tabular}{|l|l|} 
Documentario & 20 \\
minutos
\end{tabular}

Documentario

\section{curta}

metragem

curta

metragem

Documentario 21

Documentario

Documentario

Documentario

Documentario

Doc

Documentario

Documentario

Documentario

Documentario
Coor

Geografic:

$\mathrm{S} 15^{\circ} 48$

\begin{tabular}{l|c|c}
\hline 17 & $\mathrm{~S} 15^{\circ}$ \\
minutos & Mauro Giuntini & $52^{\prime} 04.6^{\prime \prime}$
\end{tabular}

$\mathrm{S} 15^{\circ} 46$

$16.4 "$

$\mathrm{S} 15^{\circ} 47$

$36.2^{\prime \prime}$

$\mathrm{S} 15^{\circ} 48$

$\mathrm{S} 15^{\circ} 48^{\prime}$

16

minutos Mauro Giuntini

$\mathrm{S} 15^{\circ} 47^{\prime}$

$\mathrm{S} 15^{\circ} 48$

$\mathrm{S} 15^{\circ} 47^{\prime}$

$\mathrm{S} 15^{\circ} 45^{\prime}$

$\mathrm{S} 15^{\circ} 45$

$\mathrm{S} 15^{\circ} 48^{\prime} \mathrm{C}$

$\mathrm{S} 15^{\circ} 48^{\prime}$

$\mathrm{S} 15^{\circ} 47$

$51^{\prime} 40.9^{\prime \prime}$

$\mathrm{S} 15^{\circ} 47^{\prime}$

$\mathrm{S} 15^{\circ} 46$

$\mathrm{S} 15^{\circ} 47$

$\mathrm{S} 15^{\circ} 52$

$55^{\prime} 18.2^{\prime \prime}$

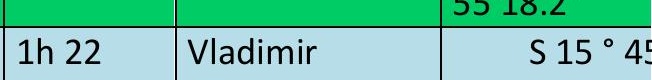

minutos Carvalho

03.4"

$\mathrm{S} 15^{\circ} 45^{\prime}$

15.6"

$\mathrm{S} 15^{\circ} 46$

$12.4^{\prime \prime}$

$\mathrm{S} 15^{\circ} 45$

13.0" 


\begin{tabular}{|c|c|c|c|c|c|c|}
\hline & Instituto de Ciências UnB & & Documentario & & & \begin{tabular}{|l}
$\mathrm{S} 15^{\circ} 47$ \\
$10.3^{\prime \prime}$
\end{tabular} \\
\hline & Teatro Nacional & & Documentario & & & \begin{tabular}{|l}
$\mathrm{S} 15^{\circ} 47$ \\
$52.3^{\prime \prime}$
\end{tabular} \\
\hline \multirow[t]{10}{*}{$\begin{array}{l}\text { Coterrâneos velhos de } \\
\text { Guerra }\end{array}$} & $\begin{array}{l}\text { Rodoviária do plano } \\
\text { piloto }\end{array}$ & 1992 & $\begin{array}{l}\text { longo } \\
\text { metragem }\end{array}$ & $\begin{array}{l}2 \mathrm{~h} 34 \\
\text { minutos }\end{array}$ & $\begin{array}{l}\text { Vladimir } \\
\text { Carvalho } \\
\end{array}$ & \begin{tabular}{|l}
$\mathrm{S} 15^{\circ} 47$ \\
$59.0^{\prime \prime}$
\end{tabular} \\
\hline & Congresso Nacional & & $\begin{array}{l}\text { longo } \\
\text { metragem }\end{array}$ & & & $\begin{array}{r}\mathrm{S} 15^{\circ} 47 \\
47^{\circ} 52^{\prime} 01.1^{\prime \prime} \\
\end{array}$ \\
\hline & Esplanada dos ministérios & & $\begin{array}{l}\text { longo } \\
\text { metragem }\end{array}$ & & & $\begin{array}{r}\mathrm{S} 15^{\circ} 47 \\
52^{\prime} 17.5^{\prime \prime}\end{array}$ \\
\hline & Plataforma da rodoviária & & $\begin{array}{l}\text { longo } \\
\text { metragem }\end{array}$ & & & \begin{tabular}{|}
$\mathrm{S} 15^{\circ} 47$ \\
$52^{\prime} 54.7^{\prime \prime}$ \\
\end{tabular} \\
\hline & W3 709 sul & & $\begin{array}{l}\text { longo } \\
\text { metragem }\end{array}$ & & & \\
\hline & Palácio do Planalto & & $\begin{array}{l}\text { longo } \\
\text { metragem }\end{array}$ & & & \begin{tabular}{|}
$\mathrm{S} 15^{\circ} 47$ \\
$51^{\prime} 40.9^{\prime \prime}$ \\
\end{tabular} \\
\hline & $\begin{array}{l}\text { Ponte presidente costa e } \\
\text { silva }\end{array}$ & & $\begin{array}{l}\text { longo } \\
\text { metragem }\end{array}$ & & & $\mathrm{S} 15^{\circ} 45^{\prime}$ \\
\hline & Monumento JK & & $\begin{array}{l}\text { longo } \\
\text { metragem }\end{array}$ & & & \begin{tabular}{|l}
$\mathrm{S} 15^{\circ} 47^{\prime} \mathrm{C}$ \\
$02.5^{\prime \prime}$
\end{tabular} \\
\hline & Catedral & & $\begin{array}{l}\text { longo } \\
\text { metragem }\end{array}$ & & & $\mathrm{S} 15^{\circ} 47$ \\
\hline & Rodoviária parte inferior & & $\begin{array}{l}\text { longo } \\
\text { metragem }\end{array}$ & & & \begin{tabular}{|l}
$\mathrm{S} 15^{\circ} 47$ \\
$52^{\prime} 59.2^{\prime \prime}$
\end{tabular} \\
\hline \multirow[t]{3}{*}{ Paisagem Natural } & & 1989 & Documentário & $\begin{array}{l}20 \\
\text { minutos }\end{array}$ & $\begin{array}{l}\text { Vladimir } \\
\text { Carvalho } \\
\end{array}$ & \\
\hline & Eixão sul & & Documentário & & & $\begin{array}{r}\mathrm{S} 15^{\circ} 48 \\
53^{\prime} 14.5^{\prime \prime} \\
\end{array}$ \\
\hline & Congresso Nacional & & Documentário & & & $\begin{array}{r}\mathrm{S} 15^{\circ} 47 \\
47^{\circ} 52^{\prime} 01.1^{\prime \prime} \\
\end{array}$ \\
\hline \multirow[t]{5}{*}{ Celeste e Estrela } & Rodoviária interestadual & 2005 & $\begin{array}{l}\text { longo } \\
\text { metragem }\end{array}$ & $\begin{array}{l}80 \\
\text { minutos }\end{array}$ & Betse de Paula & $\mathrm{S} 15^{\circ} 46$ \\
\hline & Cine Brasília & & $\begin{array}{l}\text { longo } \\
\text { metragem }\end{array}$ & & & $\mathrm{S} 15^{\circ} 48^{\prime}$ \\
\hline & Teatro Nacional & & $\begin{array}{l}\text { longo } \\
\text { metragem } \\
\end{array}$ & & & $\begin{array}{l}\mathrm{S}^{\mathrm{S}} 5^{\circ} 47^{\prime} \\
52.3^{\prime \prime}\end{array}$ \\
\hline & Asa sul & & $\begin{array}{l}\text { longo } \\
\text { metragem }\end{array}$ & & & $\mathrm{S} 15^{\circ} 48^{\prime}$ \\
\hline & Congresso Nacional & & $\begin{array}{l}\text { longo } \\
\text { metragem }\end{array}$ & & & $\begin{array}{r}\mathrm{S} 15^{\circ} 47 \\
47^{\circ} 52^{\prime} 01.1^{\prime \prime} \\
\end{array}$ \\
\hline \multirow[t]{4}{*}{ Feliz Aniversario Urbana } & Banco BRB & 1996 & Curtametragem & $\begin{array}{l}14 \\
\text { minutos }\end{array}$ & Betse de Paula & $\begin{array}{l}\mathrm{S} 15^{\circ} 47 \\
53^{\prime} 009^{\prime \prime}\end{array}$ \\
\hline & Plataforma da rodoviária & & Curtametragem & & & $S 15^{\circ} 47^{\prime}$ \\
\hline & Setor Comercial Sul & & Curtametragem & & & $S 15^{\circ} 47^{\prime}$ \\
\hline & $\begin{array}{l}\text { Estacionamento Frente } \\
\text { ao Teatro }\end{array}$ & & Curtametragem & & & $\begin{array}{r}515^{\circ} 47 \\
47^{\circ} 52^{\prime} 45.1^{\prime \prime} \\
\end{array}$ \\
\hline $\begin{array}{l}\text { A terceira margem do } \\
\text { rio }\end{array}$ & Torre TV & 1994 & $\begin{array}{l}\text { longo } \\
\text { metragem }\end{array}$ & $\begin{array}{l}\text { 1h } 38 \\
\text { minutos }\end{array}$ & $\begin{array}{l}\text { Nelson Pereira } \\
\text { dos Santos }\end{array}$ & $\begin{array}{l}\mathrm{S} 15^{\circ} 47 \\
53^{\prime} 30.4^{\prime \prime}\end{array}$ \\
\hline
\end{tabular}




\begin{tabular}{|c|c|c|c|c|c|c|}
\hline & Catedral & & $\begin{array}{l}\text { longo } \\
\text { metragem }\end{array}$ & & & $\mathrm{S} 15^{\circ} 47^{\prime}$ \\
\hline & Palácio Itamaraty & & $\begin{array}{l}\text { longo } \\
\text { metragem }\end{array}$ & & & $\begin{array}{l}S 15^{\circ} 48 \\
52^{\prime} 04.6^{\prime \prime}\end{array}$ \\
\hline & Congresso Nacional & & $\begin{array}{l}\text { longo } \\
\text { metragem }\end{array}$ & & & $\mathrm{S} 15^{\circ} 47^{\prime}$ \\
\hline & Rodoviária interestadual & & $\begin{array}{l}\text { longo } \\
\text { metragem }\end{array}$ & & & $\mathrm{S} 15^{\circ} 46$ \\
\hline & Sobradinho & & $\begin{array}{l}\text { longo } \\
\text { metragem }\end{array}$ & & & $\begin{array}{l}\mathrm{S} 15^{\circ} 38 \\
50^{\prime} 53.9^{\prime \prime}\end{array}$ \\
\hline & Cimetério de sobradinho & & $\begin{array}{l}\text { longo } \\
\text { metragem }\end{array}$ & & & $\begin{array}{l}\mathrm{S} 15^{\circ} 38 \\
50^{\prime} 00.7^{\prime \prime}\end{array}$ \\
\hline Capitalismo Selvagem & Congresso Nacional & 1993 & $\begin{array}{l}\text { longo } \\
\text { metragem }\end{array}$ & $\begin{array}{l}\text { 1h } 30 \\
\text { minutos }\end{array}$ & André Klotzel & $\mathrm{S} 15^{\circ} 47^{\prime}$ \\
\hline \multirow[t]{7}{*}{ Doces Poderes } & Aeroporto elevador & 1993 & $\begin{array}{l}\text { longo } \\
\text { metragem }\end{array}$ & $\begin{array}{l}\text { 1h42 } \\
\text { minutos }\end{array}$ & Lucia Murat & $\begin{array}{r}\mathrm{S} 15^{\circ} 52 \\
55^{\prime} 18.2^{\prime \prime} \\
\end{array}$ \\
\hline & Buraco do Tatu & & $\begin{array}{l}\text { longo } \\
\text { metragem }\end{array}$ & & & $\mathrm{S} 15^{\circ} 47$ \\
\hline & $\begin{array}{l}\text { Esplanada direção torre } \\
\text { tv }\end{array}$ & & $\begin{array}{l}\text { longo } \\
\text { metragem }\end{array}$ & & & $\begin{array}{l}\mathrm{S} 15^{\circ} 47 \\
10.1^{\prime \prime}\end{array}$ \\
\hline & Palácio do Planalto & & $\begin{array}{l}\text { longo } \\
\text { metragem }\end{array}$ & & & $\begin{array}{r}\mathrm{S} 15^{\circ} 47 \\
51^{\prime} 40.9^{\prime \prime}\end{array}$ \\
\hline & Congresso Nacional & & $\begin{array}{l}\text { longo } \\
\text { metragem }\end{array}$ & & & $\mathrm{S} 15^{\circ} 47$ \\
\hline & Conjunto Nacional & & $\begin{array}{l}\text { longo } \\
\text { metragem }\end{array}$ & & & $\begin{array}{r}\mathrm{S} 15^{\circ} 47 \\
52^{\prime} 59.1^{\prime \prime} \\
\end{array}$ \\
\hline & Eixo Torre TV & & $\begin{array}{l}\text { longo } \\
\text { metragem }\end{array}$ & & & $\mathrm{S} 15^{\circ} 47$ \\
\hline \multirow[t]{11}{*}{ Retratos de Borboleta } & Catedral & 1998 & $\begin{array}{l}\text { Curta- } \\
\text { metragem }\end{array}$ & $\begin{array}{l}10 \\
\text { minutos }\end{array}$ & Yanko del Pino & $\mathrm{S} 15^{\circ} 47$ \\
\hline & Bloco Asa sul & & $\begin{array}{l}\text { Curta- } \\
\text { metragem }\end{array}$ & & & $\begin{array}{l}\mathrm{S} 15^{\circ} 48 \\
54^{\prime} 17.5^{\prime \prime}\end{array}$ \\
\hline & $\begin{array}{l}\text { Praça frente Palácio } \\
\text { Planalto }\end{array}$ & & $\begin{array}{l}\text { Curta- } \\
\text { metragem }\end{array}$ & & & $\mathrm{S} 15^{\circ} 48^{\prime}$ \\
\hline & STF & & $\begin{array}{l}\text { Curta- } \\
\text { metragem }\end{array}$ & & & $\begin{array}{l}\text { S } 15^{\circ} 48 \\
51^{\prime} 42.6^{\prime \prime}\end{array}$ \\
\hline & Eixo monumental & & $\begin{array}{l}\text { Curta- } \\
\text { metragem }\end{array}$ & & & $\begin{array}{l}\text { S } 15^{\circ} 47 \\
36.2^{\prime \prime}\end{array}$ \\
\hline & Esplanada & & $\begin{array}{l}\text { Curta- } \\
\text { metragem }\end{array}$ & & & $\begin{array}{l}\mathrm{S}^{\mathrm{S}} \mathrm{5}^{\circ} 47^{\prime} \\
17.5^{\prime \prime}\end{array}$ \\
\hline & Congresso Nacional & & $\begin{array}{l}\text { Curta- } \\
\text { metragem }\end{array}$ & & & $\mathrm{S} 15^{\circ} 47^{\prime}$ \\
\hline & Buraco do Tatu & & $\begin{array}{l}\text { Curta- } \\
\text { metragem }\end{array}$ & & & $\mathrm{S} 15^{\circ} 47^{\prime}$ \\
\hline & Superquadra sul & & $\begin{array}{l}\text { Curta- } \\
\text { metragem }\end{array}$ & & & $\begin{array}{l}S 15^{\circ} 48 \\
54^{\prime} 17.5^{\prime \prime}\end{array}$ \\
\hline & Fonte de agua torre TV & & $\begin{array}{l}\text { Curta- } \\
\text { metragem }\end{array}$ & & & $\begin{array}{l}\mathrm{S} 15^{\circ} 47^{\prime} \\
53^{\prime} 28.9^{\prime \prime}\end{array}$ \\
\hline & Torre TV & & $\begin{array}{l}\text { Curta- } \\
\text { metragem }\end{array}$ & & & $\begin{array}{l}S 15^{\circ} 47 \\
53^{\prime} 30.4^{\prime \prime}\end{array}$ \\
\hline
\end{tabular}




\begin{tabular}{|c|c|c|c|c|c|c|}
\hline A Concepção & Congresso Nacional & 2005 & metragem & minutos & Belmonte & $\mathrm{S} 15^{\circ} 47^{\prime}$ \\
\hline & Eixão sul & & $\begin{array}{l}\text { longo } \\
\text { metragem }\end{array}$ & & & $\begin{array}{r}\mathrm{S} 15^{\circ} 48 \\
53^{\prime} 14.5^{\prime \prime}\end{array}$ \\
\hline & SQS 308 sul & & $\begin{array}{l}\text { longo } \\
\text { metragem }\end{array}$ & & & $\mathrm{S} 15^{\circ} 48$ \\
\hline & Setor Comercial Sul & & $\begin{array}{l}\text { longo } \\
\text { metragem }\end{array}$ & & & $S 15^{\circ} 47$ \\
\hline & Buraco do Tatu & & $\begin{array}{l}\text { longo } \\
\text { metragem }\end{array}$ & & & S $15^{\circ} 47$ \\
\hline & Aeroporto & & $\begin{array}{l}\text { longo } \\
\text { metragem }\end{array}$ & & & $\begin{array}{r}\mathrm{S} 15^{\circ} 52 \\
55^{\prime} 18.2^{\prime \prime} \\
\end{array}$ \\
\hline & Bloco $\mathrm{K}$ asa sul & & $\begin{array}{l}\text { longo } \\
\text { metragem }\end{array}$ & & & $\begin{array}{l}\mathrm{S} 15^{\circ} 48 \\
53^{\prime} 49.2^{\prime \prime}\end{array}$ \\
\hline & Feira da Ceilândia & & $\begin{array}{l}\text { longo } \\
\text { metragem }\end{array}$ & & & $\begin{array}{r}\mathrm{S} 15^{\circ} 49 \\
06^{\prime} 18.88^{\prime \prime} \\
\end{array}$ \\
\hline 5 filmes estrangeiros & SCS 303/302 & 1997 & Curtametragem & $\begin{array}{l}13 \\
\text { minutos } \\
\end{array}$ & $\begin{array}{l}\text { Jose Eduardo } \\
\text { Belmonte }\end{array}$ & $\begin{array}{r}\mathrm{S} 15^{\circ} 48 \\
53^{\prime} 25.2^{\prime \prime} \\
\end{array}$ \\
\hline & Eixão sul & & Curtametragem & & & $\mathrm{S} 15^{\circ} 48$ \\
\hline & Setor de Embaixada & & Curtametragem & & & $\mathrm{S} 15^{\circ} 48^{\prime}$ \\
\hline Subterrâneos & subsolo do conic & 2003 & Curtametragem & 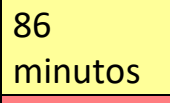 & $\begin{array}{l}\text { José eduardo } \\
\text { Belmonte }\end{array}$ & $\mathrm{S} 15^{\circ} 47$ \\
\hline Brasileirarios & Conic & 1986 & Curtametragem & $\begin{array}{l}10 \\
\text { minutos } \\
\text { e } 30 \\
\text { segundos }\end{array}$ & $\begin{array}{l}\text { Zuleica Porto e } \\
\text { Sergio Bazzi }\end{array}$ & $\mathrm{S} 15^{\circ} 47$ \\
\hline & Teatro Nacional & & Curtametragem & & & $\begin{array}{l}\mathrm{S} 15^{\circ} 47 \\
52^{\prime} 52.3^{\prime \prime}\end{array}$ \\
\hline & Buraco do Tatu & & Curtametragem & & & $\mathrm{S} 15^{\circ} 47^{\prime}$ \\
\hline & Rua costado do Conic & & Curtametragem & & & $S 15^{\circ} 47^{\prime}$ \\
\hline & Exinho norte & & Curtametragem & & & $\begin{array}{r}\mathrm{S} 15^{\circ} 47 \\
47^{\circ} 52^{\prime} 47.5^{\prime \prime} \\
\end{array}$ \\
\hline & $\begin{array}{l}\text { Passarela subterrâneas } \\
\text { entre quadras }\end{array}$ & & Curtametragem & & & $\mathrm{S} 15^{\circ} 45^{\prime}$ \\
\hline & Setor bancário norte & & Curtametragem & & & $\begin{array}{r}\mathrm{S} 15^{\circ} 47 \\
47^{\circ} 52^{\prime} 50.2^{\prime \prime} \\
\end{array}$ \\
\hline & Escada Teatro nacional & & Curtametragem & & & $S 15^{\circ} 47^{\prime}$ \\
\hline $\begin{array}{l}\text { Tortura selvagem a } \\
\text { grade }\end{array}$ & $\begin{array}{l}\text { Congresso Nacional por } \\
\text { trás }\end{array}$ & 2001 & $\begin{array}{l}\text { longo } \\
\text { metragem }\end{array}$ & $\begin{array}{l}75 \\
\text { minutos }\end{array}$ & Afonso Brazza & $\begin{array}{r}\mathrm{S} 15^{\circ} 48 \\
51^{\prime} 44.0^{\prime \prime}\end{array}$ \\
\hline & Teatro Nacional & & $\begin{array}{l}\text { longo } \\
\text { metragem }\end{array}$ & & & $\begin{array}{l}\mathrm{S}^{\prime} 15^{\circ} 47 \\
52.3^{\prime \prime}\end{array}$ \\
\hline & Conjunto Nacional & & $\begin{array}{l}\text { longo } \\
\text { metragem }\end{array}$ & & & $\begin{array}{r}\mathrm{S} 15^{\circ} 47 \\
52^{\prime} 59.1^{\prime \prime} \\
\end{array}$ \\
\hline & Conic & & $\begin{array}{l}\text { longo } \\
\text { metragem }\end{array}$ & & & $S 15^{\circ} 47$ \\
\hline & $\begin{array}{l}\text { Estacionamento atrás do } \\
\text { conic }\end{array}$ & & $\begin{array}{l}\text { longo } \\
\text { metragem }\end{array}$ & & & S $15^{\circ} 46^{\prime}$ \\
\hline
\end{tabular}




\begin{tabular}{|c|c|c|c|c|c|c|}
\hline & Hotel Nacional & & $\begin{array}{l}\text { longo } \\
\text { metragem }\end{array}$ & & & $\mathrm{S} 15^{\circ} 47$ \\
\hline & Torre TV & & $\begin{array}{l}\text { longo } \\
\text { metragem }\end{array}$ & & & $\begin{array}{l}\text { S } 15^{\circ} 47 \\
53^{\prime} 30.4^{\prime \prime}\end{array}$ \\
\hline & Ponte das Garças & & $\begin{array}{l}\text { longo } \\
\text { metragem }\end{array}$ & & & $\begin{array}{l}\text { S } 15^{\circ} 50 \\
51.9^{\prime \prime}\end{array}$ \\
\hline & Pontão do lago sul & & $\begin{array}{l}\text { longo } \\
\text { metragem }\end{array}$ & & & $\begin{array}{l}\text { S } 15^{\circ} 49 \\
19.6^{\prime \prime}\end{array}$ \\
\hline \multirow[t]{7}{*}{ NO Eixo da morte } & Setor de diversões sul & 1998 & $\begin{array}{l}\text { longo } \\
\text { metragem }\end{array}$ & $\begin{array}{l}78 \\
\text { minutos }\end{array}$ & Afonso Brazza & $\mathrm{S} 15^{\circ} 47$ \\
\hline & Torre TV & & $\begin{array}{l}\text { longo } \\
\text { metragem }\end{array}$ & & & $\begin{array}{l}\text { S } 15^{\circ} 47 \\
53^{\prime} 30.4^{\prime \prime}\end{array}$ \\
\hline & $\begin{array}{l}\text { Corpo de bombeiros final } \\
\text { asa norte }\end{array}$ & & $\begin{array}{l}\text { longo } \\
\text { metragem }\end{array}$ & & & $\begin{array}{l}\text { S } 15^{\circ} 44 \\
54^{\prime} 19.2^{\prime \prime} \\
\end{array}$ \\
\hline & $\begin{array}{l}\text { Plataforma Rodoviária } \\
\text { sentido torre tv }\end{array}$ & & $\begin{array}{l}\text { longo } \\
\text { metragem }\end{array}$ & & & $S 15^{\circ} 47$ \\
\hline & Ponte das Garças & & $\begin{array}{l}\text { longo } \\
\text { metragem }\end{array}$ & & & $\begin{array}{l}\text { S } 15^{\circ} 50 \\
51.9^{\prime \prime}\end{array}$ \\
\hline & Casa lago sul & & $\begin{array}{l}\text { longo } \\
\text { metragem }\end{array}$ & & & $\mathrm{S} 15^{\circ} 49$ \\
\hline & Interior do Conic & & $\begin{array}{l}\text { longo } \\
\text { metragem }\end{array}$ & & & $S 15^{\circ} 47$ \\
\hline Inferno no Gama & $\begin{array}{l}\text { Núcleo Rural Ponte alta - } \\
\text { Gama }\end{array}$ & 1993 & $\begin{array}{l}\text { longo } \\
\text { metragem }\end{array}$ & $\begin{array}{l}\text { 1h } 15 \\
\text { minutos }\end{array}$ & Afonso Bazza & $\begin{array}{r}S 15^{\circ} 58^{\prime} \\
\text { IW48 } \\
\end{array}$ \\
\hline $\begin{array}{l}\text { Gringo não perdoa, } \\
\text { Mata }\end{array}$ & $\begin{array}{l}\text { Núcleo Rural Ponte alta - } \\
\text { Gama }\end{array}$ & 1995 & $\begin{array}{l}\text { longo } \\
\text { metragem }\end{array}$ & $\begin{array}{l}\text { 1h } 30 \\
\text { minutos }\end{array}$ & Afonso Bazza & $\begin{array}{r}S 15^{\circ} 58^{\prime} \\
\text { IW } 48^{\circ} 06^{\prime} 10 .\end{array}$ \\
\hline \multirow[t]{2}{*}{ Momento Trágico } & Bar beirute & 2003 & Curtametragem & $\begin{array}{l}17 \\
\text { minutos }\end{array}$ & Cibele Amaral & $\mathrm{S} 15^{\circ} 49$ \\
\hline & CLN 313 & & Curtametragem & & & $\begin{array}{l}\text { S } 15^{\circ} 45 \\
34.5^{\prime \prime} \\
\end{array}$ \\
\hline \multirow[t]{4}{*}{ Flor de Obsessão } & Academia de ginástica & 2000 & $\begin{array}{l}\text { Curta } \\
\text { metragem }\end{array}$ & $\begin{array}{l}9 \\
\text { minutos } \\
\end{array}$ & Cibele Amaral & $\begin{array}{r}S 15^{\circ} 45^{\prime} \\
47^{\circ} 53^{\prime} 45.84^{\prime \prime} \\
\end{array}$ \\
\hline & parque na cidade & & Curtametragem & & & $\mathrm{S} 15^{\circ} 48^{\prime}$ \\
\hline & setor comercial norte & & Curtametragem & & & $\begin{array}{r}\mathrm{S} 15^{\circ} 47^{\prime} \\
47^{\circ} 53^{\prime} 11.47^{\prime}\end{array}$ \\
\hline & \begin{tabular}{|l} 
núcleo de dança de \\
Brasília \\
\end{tabular} & & Curtametragem & & & $\begin{array}{r}\mathrm{S} 15^{\circ} 47^{\prime} \\
47^{\circ} 52^{\prime} 34.05^{\prime} \\
\end{array}$ \\
\hline \multirow[t]{5}{*}{ Rap da Ceilândia } & & 2005 & Documentario & \begin{tabular}{|l}
15 \\
minutos \\
e 32 \\
segundo \\
\end{tabular} & Adirley Queiroz & \\
\hline & Caixa de água & & Documentario & & & $\begin{array}{r}S 15^{\circ} 49 \\
48^{\circ} 06^{\prime} 18.85^{\prime \prime}\end{array}$ \\
\hline & QNN 08 & & Documentario & & & $\begin{array}{r}\text { S } 15^{\circ} 49 \\
48^{\circ} 06^{\prime} 27.9^{\prime \prime} \\
\end{array}$ \\
\hline & Feira da Ceilândia & & Documentario & & & $\begin{array}{r}\text { S } 15^{\circ} 49 \\
06^{\prime} 18.88^{\prime \prime}\end{array}$ \\
\hline & QNQ setor O & & Documentario & & & $\mathrm{S} 15^{\circ} 36^{\prime}$ \\
\hline
\end{tabular}




\begin{tabular}{|c|c|c|c|c|c|c|}
\hline \multirow[t]{9}{*}{ A dança da espera } & $\begin{array}{l}\text { Cemitério parque da } \\
\text { esperança }\end{array}$ & 2000 & curtametragem & $\begin{array}{l}16 \\
\text { minutos }\end{array}$ & $\begin{array}{l}\text { André } \\
\text { Nascimento }\end{array}$ & $\mathrm{S} 15^{\circ} 49^{\prime}$ \\
\hline & $\begin{array}{l}\text { Parada de ônibus eixo } \\
\text { monumental }\end{array}$ & & curtametragem & & & \\
\hline & Buraco do Tatu & & curtametragem & & & S $15^{\circ} 47$ \\
\hline & Setor Comercial Sul & & curtametragem & & & S $15^{\circ} 47$ \\
\hline & Bloco $208 \backslash 209$ norte & & curtametragem & & & $\begin{array}{r}\mathrm{S} 15^{\circ} 46^{\prime} \\
\mathrm{W} 47^{\circ} 52^{\prime} 45.0\end{array}$ \\
\hline & SCRN 706\707 & & curtametragem & & & $\begin{array}{r}S 15^{\circ} 46 \\
47^{\circ} 53^{\prime} 21.44^{\prime}\end{array}$ \\
\hline & W3 norte $506 \backslash 507$ & & curtametragem & & & $\begin{array}{r}\mathrm{S} 15^{\circ} 46^{\prime} \\
\mathrm{W} 47^{\circ} 53^{\prime} 22.5\end{array}$ \\
\hline & $\begin{array}{l}\text { Setor de oficina norte } \\
704 \backslash 703\end{array}$ & & curtametragem & & & $\mathrm{S} 15^{\circ} 46^{\prime}$ \\
\hline & Fonte de Água Torre TV & & curtametragem & & & $\begin{array}{l}\text { S } 15^{\circ} 47 \\
53^{\prime} 28.9^{\prime \prime}\end{array}$ \\
\hline Flor Madruga & Secretaria de cultura & 2000 & $\begin{array}{l}\text { curta } \\
\text { metragem }\end{array}$ & $\begin{array}{l}4 \\
\text { minutos }\end{array}$ & Nôga Ribeiro & $\mathrm{S} 15^{\circ} 47^{\prime}$ \\
\hline \multirow[t]{5}{*}{ Louco por Cinema } & & 1994 & longametragem & $\begin{array}{l}\text { 1h } 40 \\
\text { minutos }\end{array}$ & $\begin{array}{l}\text { André luiz de } \\
\text { oliveira }\end{array}$ & \\
\hline & $\begin{array}{l}\text { Polo de cinema de } \\
\text { sobradinho }\end{array}$ & & longametragem & & & $\mathrm{S} 15^{\circ} 36^{\prime !}$ \\
\hline & Casa asa sul & & longametragem & & & $\mathrm{S} 15^{\circ} 48^{\prime}$ \\
\hline & Escola de agronomia USP & & longametragem & & & $\mathrm{S} 15^{\circ} 35^{\prime \prime}$ \\
\hline & Cine Brasília & & longametragem & & & $\mathrm{S} 15^{\circ} 48^{\prime}$ \\
\hline \multirow[t]{3}{*}{ A Lente e Janela } & Eixinho norte & 2005 & $\begin{array}{l}\text { curta } \\
\text { metragem }\end{array}$ & $\begin{array}{l}12 \\
\text { minutos }\end{array}$ & $\begin{array}{l}\text { Marcius } \\
\text { Barbieri }\end{array}$ & $\mathrm{S} 15^{\circ} 47^{\prime}$ \\
\hline & Tesourinha norte & & $\begin{array}{l}\text { curta } \\
\text { metragem }\end{array}$ & & & $\mathrm{S} 15^{\circ} 45^{\prime}$ \\
\hline & Passagem Subterrânea & & $\begin{array}{l}\text { curta } \\
\text { metragem }\end{array}$ & & & $\mathrm{S} 15^{\circ} 45^{\prime}$ \\
\hline \multirow[t]{8}{*}{ As vidas de Maria } & Santuário Dom Bosco & 2005 & $\begin{array}{l}\text { Longa } \\
\text { metragem }\end{array}$ & $\begin{array}{l}\text { 1h } 15 \\
\text { minutos }\end{array}$ & \begin{tabular}{|l} 
Renato \\
Barbiere
\end{tabular} & $\mathrm{S} 15^{\circ} 48^{\prime}$ \\
\hline & STF & & \begin{tabular}{|l|} 
Longa \\
metragem
\end{tabular} & & & $\begin{array}{l}\text { S } 15^{\circ} 48 \\
51^{\prime} 42.6^{\prime \prime} \\
\end{array}$ \\
\hline & Buraco do Tatu & & \begin{tabular}{|l|} 
Longa \\
metragem
\end{tabular} & & & S $15^{\circ} 47$ \\
\hline & Torre TV & & \begin{tabular}{|l|} 
Longa \\
metragem
\end{tabular} & & & $\begin{array}{l}\text { S } 15^{\circ} 47 \\
53^{\prime} 28.9^{\prime \prime} \\
\end{array}$ \\
\hline & Esplanada dos ministérios & & \begin{tabular}{|l|} 
Longa \\
metragem
\end{tabular} & & & $515^{\circ} 47$ \\
\hline & Hospital de Base & & \begin{tabular}{|l|} 
Longa \\
metragem
\end{tabular} & & & $\mathrm{S} 15^{\circ} 47$ \\
\hline & Gramado UnB & & \begin{tabular}{|l|} 
Longa \\
metragem
\end{tabular} & & & $\begin{array}{l}\mathrm{S} 15^{\circ} 4 ! \\
03.4^{\prime \prime}\end{array}$ \\
\hline & $\begin{array}{l}\text { Casarão Histórico de } \\
\text { Planaltina }\end{array}$ & & $\begin{array}{l}\text { Longa } \\
\text { metragem }\end{array}$ & & & $\begin{array}{r}S 15^{\circ} 37 \\
47^{\circ} 39^{\prime} 43.49^{\prime \prime}\end{array}$ \\
\hline
\end{tabular}




\begin{tabular}{|c|c|c|c|c|c|c|}
\hline & $\begin{array}{l}\text { Cemitéro parque da } \\
\text { esperança }\end{array}$ & & $\begin{array}{l}\text { Longa } \\
\text { metragem }\end{array}$ & & & $\mathrm{S} 15^{\circ} 49^{\prime}$ \\
\hline & Lago norte & & $\begin{array}{l}\text { Longa } \\
\text { metragem }\end{array}$ & & & \\
\hline & Igreja 307\308 sul & & $\begin{array}{l}\text { Longa } \\
\text { metragem }\end{array}$ & & & $\mathrm{S} 15^{\circ} 48$ \\
\hline & Paranoá bosque & & $\begin{array}{l}\text { Longa } \\
\text { metragem }\end{array}$ & & & S $15^{\circ} 46$ \\
\hline & Catetinho & & $\begin{array}{l}\text { Longa } \\
\text { metragem }\end{array}$ & & & $\mathrm{S} 15^{\circ} 56^{\prime}$ \\
\hline & Palácio alvorada & & $\begin{array}{l}\text { Longa } \\
\text { metragem }\end{array}$ & & & $\mathrm{S} 15^{\circ} 47^{\prime}$ \\
\hline & Catedral & & $\begin{array}{l}\text { Longa } \\
\text { metragem }\end{array}$ & & & $\mathrm{S} 15^{\circ} 47$ \\
\hline & Eixão sul & & $\begin{array}{l}\text { Longa } \\
\text { metragem }\end{array}$ & & & $\begin{array}{l}\text { S } 15^{\circ} 48 \\
53^{\prime} 14.5^{\prime \prime}\end{array}$ \\
\hline & Esplanada & & $\begin{array}{l}\text { Longa } \\
\text { metragem }\end{array}$ & & & $\begin{array}{l}\mathrm{S}^{\mathrm{S}} 5^{\circ} 47 \\
17.5^{\prime \prime}\end{array}$ \\
\hline $\begin{array}{l}\text { Teodoro Freire o } \\
\text { guardião do rito }\end{array}$ & $\begin{array}{l}\text { Cetro de Tradições } \\
\text { populares de Sobradinho }\end{array}$ & 2003 & Documentario & $\begin{array}{l}20 \\
\text { minutos } \\
\text { e } 13 \\
\text { segundo }\end{array}$ & William Alves & $\mathrm{S} 15^{\circ} 38^{\prime}$ \\
\hline 100 anos de perdão & SCS 106 & 2000 & $\begin{array}{l}\text { curta } \\
\text { metragem }\end{array}$ & $\begin{array}{l}7 \\
\text { minutos } \\
\text { e } 35 \\
\text { segundo }\end{array}$ & William Alves & $\mathrm{S} 15^{\circ} 48^{\prime}$ \\
\hline $\mathrm{O}$ vidreiro & ICC norte UnB & 1997 & $\begin{array}{l}\text { Curta } \\
\text { metragem }\end{array}$ & $\begin{array}{l}27 \\
\text { minutos }\end{array}$ & $\begin{array}{l}\text { Marcos de } \\
\text { Souza Mendes }\end{array}$ & $\begin{array}{l}\text { S } 15^{\circ} 47 \\
10.3^{\prime \prime}\end{array}$ \\
\hline \multirow[t]{7}{*}{$\begin{array}{l}\text { Brasília do projeto ao } \\
\text { concreto I }\end{array}$} & Arquivo Público & 1991 & $\begin{array}{l}\text { Curta } \\
\text { metragem }\end{array}$ & $\begin{array}{l}24 \\
\text { minutos }\end{array}$ & $\begin{array}{l}\text { Marcos de } \\
\text { Souza Mendes }\end{array}$ & $\begin{array}{r}\mathrm{S} 15^{\circ} 46^{\prime} \\
47^{\circ} 54^{\prime} 38.01^{\prime} \\
\end{array}$ \\
\hline & Esplanada dos ministérios & & $\begin{array}{l}\text { Curta } \\
\text { metragem }\end{array}$ & & & $\begin{array}{l}\text { S } 15^{\circ} 47 \\
52^{\prime} 17.5^{\prime \prime}\end{array}$ \\
\hline & Rodoviária plano piloto & & $\begin{array}{l}\text { Curta } \\
\text { metragem }\end{array}$ & & & $\begin{array}{l}\text { S } 15^{\circ} 47 \\
59.0^{\prime \prime}\end{array}$ \\
\hline & Conic & & $\begin{array}{l}\text { Curta } \\
\text { metragem }\end{array}$ & & & $\mathrm{S} 15^{\circ} 47$ \\
\hline & Setor Bancário sul & & $\begin{array}{l}\text { Curta } \\
\text { metragem }\end{array}$ & & & $\mathrm{S} 15^{\circ} 48^{\prime}$ \\
\hline & Catedral & & $\begin{array}{l}\text { Curta } \\
\text { metragem }\end{array}$ & & & $\mathrm{S} 15^{\circ} 47$ \\
\hline & Teatro Nacional & & $\begin{array}{l}\text { Curta } \\
\text { metragem }\end{array}$ & & & $\begin{array}{l}\text { S } 15^{\circ} 47 \\
52.3^{\prime \prime}\end{array}$ \\
\hline \multirow[t]{2}{*}{$\begin{array}{l}\text { Brasília do projeto ao } \\
\text { concreto I I }\end{array}$} & Casa lago sul & 1991 & $\begin{array}{l}\text { Curta } \\
\text { metragem }\end{array}$ & $\begin{array}{l}24 \\
\text { minutos }\end{array}$ & $\begin{array}{l}\text { Marcos de } \\
\text { Souza Mendes }\end{array}$ & S $15^{\circ} 49$ \\
\hline & Senado federal & & $\begin{array}{l}\text { Curta } \\
\text { metragem }\end{array}$ & & & $\mathrm{S} 15^{\circ} 47^{\prime !}$ \\
\hline
\end{tabular}




\begin{tabular}{|c|c|c|c|c|c|c|}
\hline & Casa quadra w3 sul & & \begin{tabular}{|l} 
Curta \\
metragem
\end{tabular} & & & $\mathrm{S} 15^{\circ} 48^{\prime}$ \\
\hline & Eixo Monumental & & \begin{tabular}{|l|} 
Curta \\
metragem
\end{tabular} & & & $\begin{array}{l}{\mathrm{S} 15^{\circ} 47}_{36.2^{\prime \prime}} \\
\end{array}$ \\
\hline & Instituto de Ciências Unb & & \begin{tabular}{|l|} 
Curta \\
metragem
\end{tabular} & & & \begin{tabular}{|l}
${\mathrm{S} 15^{\circ} 47}_{10.3^{\prime \prime}}$ \\
\end{tabular} \\
\hline & SCS 106 Sul & & $\begin{array}{l}\text { Curta } \\
\text { metragem }\end{array}$ & & & $\mathrm{S} 15^{\circ} 48^{\prime} \mathrm{C}$ \\
\hline \multirow[t]{7}{*}{ O cego que gritava luz } & Plataforma da rodoviária & 1996 & $\begin{array}{l}\text { longo } \\
\text { metragem }\end{array}$ & $\begin{array}{l}\text { 1h } 25 \\
\text { minutos }\end{array}$ & $\begin{array}{l}\text { Jão Batista } \\
\text { Andrade }\end{array}$ & \begin{tabular}{|}
$\mathrm{S} 15^{\circ} 47$ \\
$52^{\prime} 54.7^{\prime \prime}$
\end{tabular} \\
\hline & $\begin{array}{l}\begin{array}{l}\text { Lago Paranoá vila } \\
\text { planalto }\end{array} \\
\end{array}$ & & \begin{tabular}{|l|} 
longo \\
metragem
\end{tabular} & & & $\begin{array}{l}\text { S } 15^{\circ} 47 \\
50^{\prime} 36.1^{\prime \prime}\end{array}$ \\
\hline & Conjunto Nacional & & \begin{tabular}{|l|} 
longo \\
metragem
\end{tabular} & & & $\begin{array}{l}\mathrm{S} 15^{\circ} 47 \\
52^{\prime} 59.1^{\prime \prime}\end{array}$ \\
\hline & $\begin{array}{l}\text { Congresso Nacional por } \\
\text { tras }\end{array}$ & & \begin{tabular}{|l|} 
longo \\
metragem
\end{tabular} & & & $\begin{array}{r}\mathrm{S} 15^{\circ} 48 \\
51^{\prime} 44.0^{\prime \prime}\end{array}$ \\
\hline & Palácio Planalto & & \begin{tabular}{|l|} 
longo \\
metragem
\end{tabular} & & & $\begin{array}{l}\mathrm{S} 15^{\circ} 47 \\
51^{\prime} 40.9^{\prime \prime}\end{array}$ \\
\hline & $\begin{array}{l}\text { Plataforma rodoviária } \\
\text { torre tv }\end{array}$ & & $\begin{array}{l}\text { longo } \\
\text { metragem }\end{array}$ & & & $\begin{array}{l}\mathrm{S} 15^{\circ} 47 \\
53^{\prime} 01.3^{\prime \prime}\end{array}$ \\
\hline & Torre TV & & \begin{tabular}{|l|} 
longo \\
metragem
\end{tabular} & & & $\begin{array}{l}\mathrm{S} 15^{\circ} 47 \\
53^{\prime} 30.4^{\prime \prime}\end{array}$ \\
\hline Ceu Aberto & $\begin{array}{l}\text { Rampla de Palácio } \\
\text { Planalto }\end{array}$ & 1985 & Documentário & $\begin{array}{l}78 \\
\text { minutos }\end{array}$ & $\begin{array}{l}\text { João Batista de } \\
\text { Andrade }\end{array}$ & $\begin{array}{l}\text { S } 15^{\circ} 47 \\
51^{\prime} 40.9^{\prime \prime}\end{array}$ \\
\hline \multirow[t]{5}{*}{ Sinistro } & $503 \mathrm{sul}$ & 2000 & Curtametragem & $\begin{array}{l}17 \\
\text { minutos } \\
\end{array}$ & Rene Sampaio & \begin{tabular}{|}
$\mathrm{S} 15^{\circ} 48$ \\
$53^{\prime} 42.4^{\prime \prime}$ \\
\end{tabular} \\
\hline & Hospital de Base & & Curtametragem & & & $\mathrm{S} 15^{\circ} 47$ \\
\hline & W3 sul perto do Itaú & & Curtametragem & & & $\begin{array}{l}\mathrm{S} 15^{\circ} 48 \\
53^{\prime} 50.9^{\prime \prime}\end{array}$ \\
\hline & Ginásio Nilson Nelson & & Curtametragem & & & $\mathrm{S} 15^{\circ} 46$ \\
\hline & Eixo Museu JK & & Curtametragem & & & $\mathrm{S} 15^{\circ} 47$ \\
\hline \multirow[t]{5}{*}{ A volta do candango } & Congresso Nacional & 2006 & Curtametragem & $\begin{array}{l}6 \\
\text { minutos }\end{array}$ & $\begin{array}{l}\text { Felipe Gontijo } \\
\text { e Eric Aben- } \\
\text { athar }\end{array}$ & S $15^{\circ} 47$ \\
\hline & Plataforma rodoviária & & Curtametragem & & & $\begin{array}{l}\mathrm{S} 15^{\circ} 47 \\
52^{\prime} 54.7^{\prime \prime}\end{array}$ \\
\hline & Escada Rodoviária & & Curtametragem & & & $\begin{array}{r}\mathrm{S} 15^{\circ} 47 \\
52^{\prime} 56.5^{\prime \prime}\end{array}$ \\
\hline & Camelo Rodoviária & & Curtametragem & & & $\begin{array}{c}\mathrm{S} 15^{\circ} 47 \\
52^{\prime} 58.0^{\prime \prime}\end{array}$ \\
\hline & $\begin{array}{l}\text { Parte inferior da } \\
\text { rodoviária }\end{array}$ & & Curtametragem & & & \begin{tabular}{|}
$\mathrm{S} 15^{\circ} 47$ \\
$52^{\prime} 55.2^{\prime \prime}$
\end{tabular} \\
\hline \multirow[t]{3}{*}{ A TV que virou estrela } & parque da cidade & 1993 & $\begin{array}{l}\text { Longa } \\
\text { metragem }\end{array}$ & $\begin{array}{l}77 \\
\text { minutos }\end{array}$ & $\begin{array}{l}\text { Marciu Curi e } \\
\text { Yanko del Pino }\end{array}$ & $\mathrm{S} 15^{\circ} 48^{\prime}$ \\
\hline & Esplanada & & $\begin{array}{l}\text { Longa } \\
\text { metragem }\end{array}$ & & & $\begin{array}{l}\mathrm{S} 15^{\circ} 47 \\
52^{\prime} 17.5^{\prime \prime}\end{array}$ \\
\hline & nadaMAR & & $\begin{array}{l}\text { Longa } \\
\text { metragem }\end{array}$ & & & $\begin{array}{l}\mathrm{S} 15^{\circ} 47 \\
52.3^{\prime \prime}\end{array}$ \\
\hline
\end{tabular}




\begin{tabular}{|c|c|c|c|c|c|c|}
\hline & Guara QE 25 & & $\begin{array}{l}\text { Longa } \\
\text { metragem }\end{array}$ & & & $\begin{array}{r}\mathrm{S} 15^{\circ} 49^{\prime} \\
47^{\circ} 58^{\prime} 25.45^{\prime \prime}\end{array}$ \\
\hline \multirow[t]{8}{*}{ Brasília da TV Senado } & Eixão & 2002 & $\begin{array}{l}\text { Curta } \\
\text { metragem }\end{array}$ & $\begin{array}{l}20 \\
\text { minutos }\end{array}$ & Maria Maia & $\begin{array}{l}\mathrm{S} 15^{\circ} 48 \\
53^{\prime} 14.5^{\prime \prime}\end{array}$ \\
\hline & Teatro Nacional & & $\begin{array}{l}\text { Curta } \\
\text { metragem }\end{array}$ & & & $\begin{array}{l}\mathrm{S} 15^{\circ} 47 \\
52.3^{\prime \prime}\end{array}$ \\
\hline & Congresso Nacional & & $\begin{array}{l}\text { Curta } \\
\text { metragem }\end{array}$ & & & $\begin{array}{r}S 15^{\circ} 47 \\
47^{\circ} 52^{\prime} 01.1^{\prime \prime}\end{array}$ \\
\hline & Palácio Alvorada & & $\begin{array}{l}\text { Curta } \\
\text { metragem }\end{array}$ & & & $\mathrm{S} 15^{\circ} 47^{\prime}$ \\
\hline & Catedral & & $\begin{array}{l}\text { Curta } \\
\text { metragem }\end{array}$ & & & $\mathrm{S} 15^{\circ} 47$ \\
\hline & Palácio Itamaraty & & $\begin{array}{l}\text { Curta } \\
\text { metragem }\end{array}$ & & & $\begin{array}{l}\text { S } 15^{\circ} 48 \\
52^{\prime} 04.6^{\prime \prime}\end{array}$ \\
\hline & STF & & $\begin{array}{l}\text { Curta } \\
\text { metragem }\end{array}$ & & & $\begin{array}{l}\text { S } 15^{\circ} 48 \\
51^{\prime} 42.6^{\prime \prime}\end{array}$ \\
\hline & Rodoviária plano piloto & & $\begin{array}{l}\text { Curta } \\
\text { metragem }\end{array}$ & & & $\begin{array}{l}\text { S } 15^{\circ} 47 \\
59.0^{\prime \prime}\end{array}$ \\
\hline \multirow[t]{5}{*}{$\begin{array}{l}\text { Maestro Jorge Antunes, } \\
\text { Polêmica e } \\
\text { Modernidade }\end{array}$} & Biblioteca Unb & 2005 & Documentário & $\begin{array}{l}54 \\
\text { minutos } \\
\text { com } 47 \\
\text { segundo }\end{array}$ & Carlos del Pino & \\
\hline & Icc norte Unb & & Documentário & & & $\begin{array}{l}\mathrm{S} 15^{\circ} 47 \\
10.3^{\prime \prime}\end{array}$ \\
\hline & Setor Comercial Sul & & Documentário & & & $\mathrm{S} 15^{\circ} 47^{\prime}$ \\
\hline & Teatro Nacional & & Documentário & & & $\begin{array}{l}\mathrm{S} 15^{\circ} 47 \\
52.3^{\prime \prime}\end{array}$ \\
\hline & Torre TV & & Documentário & & & $\begin{array}{l}\mathrm{S} 15^{\circ} 47 \\
53^{\prime} 30.4^{\prime \prime}\end{array}$ \\
\hline Brasília a última utopia & & 1989 & $\begin{array}{l}\text { Longa- } \\
\text { metragem }\end{array}$ & $\begin{array}{l}105 \\
\text { minutos }\end{array}$ & $\begin{array}{l}\text { Vladimir } \\
\text { Carvalho, } \\
\text { Pedro Jorge de } \\
\text { Castro, } \\
\text { Roberto Pires, } \\
\text { Pedro Anísio, } \\
\text { Moacir de } \\
\text { Oliveira, } \\
\text { Geraldo } \\
\text { Moraes }\end{array}$ & \\
\hline \multirow[t]{4}{*}{ O sinal da Cruz } & Esplanada dos Ministérios & 1989 & Documentário & & $\begin{array}{l}\text { Pedro Jorde de } \\
\text { Castro }\end{array}$ & $\begin{array}{l}S 15^{\circ} 47 \\
52^{\prime} 17.5^{\prime \prime}\end{array}$ \\
\hline & Teatro Nacional & & Documentário & & & $\begin{array}{l}\text { S } 15^{\circ} 47 \\
52.3^{\prime \prime}\end{array}$ \\
\hline & instituto de Ciências UnB & & Documentário & & & $\begin{array}{l}\text { S } 15^{\circ} 47 \\
10.3^{\prime \prime}\end{array}$ \\
\hline & Congresso Nacional & & Documentário & & & $\begin{array}{r}515^{\circ} 47 \\
47^{\circ} 52^{\prime} 01.1^{\prime \prime} \\
\end{array}$ \\
\hline Suíte Brasília & Museu de Arte de Brasília & 1989 & Documentário & $\begin{array}{l}20 \\
\text { minutos }\end{array}$ & $\begin{array}{l}\text { Moacir de } \\
\text { Oliveira }\end{array}$ & $\begin{array}{r}S 15^{\circ} 47^{\prime} \\
47^{\circ} 49^{\prime} 50.76^{\prime \prime}\end{array}$ \\
\hline
\end{tabular}




\begin{tabular}{|c|c|c|c|c|c|c|}
\hline & Congresso Nacional & & Documentário & & & $\begin{array}{r}\mathrm{S} 15^{\circ} 47 \\
47^{\circ} 52^{\prime} 01.1^{\prime \prime} \\
\end{array}$ \\
\hline & Tesourinha norte & & Documentário & & & $\mathrm{S} 15^{\circ} 45^{\prime} \mathrm{C}$ \\
\hline & STF & & Documentário & & & $\begin{array}{r}\mathrm{S} 15^{\circ} 48 \\
51^{\prime} 42.6^{\prime \prime} \\
\end{array}$ \\
\hline & Monumento JK & & Documentário & & & $\begin{array}{l}\mathrm{S} 15^{\circ} 47^{\prime} \mathrm{C} \\
02.5^{\prime \prime}\end{array}$ \\
\hline & Palácio Itamaraty & & Documentário & & & $\begin{array}{r}\mathrm{S} 15^{\circ} 48 \\
52^{\prime} 04.6^{\prime \prime} \\
\end{array}$ \\
\hline & Pateão da Pátria & & Documentário & & & $\begin{array}{r}\mathrm{S} 15^{\circ} 48^{\prime} \\
47^{\circ} 51^{\prime} 36.65^{\prime \prime} \\
\end{array}$ \\
\hline \multirow[t]{9}{*}{ A volta do Candango } & Congresso Nacional & 1989 & Documentário & $\begin{array}{l}25 \\
\text { minutos }\end{array}$ & Roberto Pires & $\begin{array}{r}S 15^{\circ} 47 \\
47^{\circ} 52^{\prime} 01.1^{\prime \prime}\end{array}$ \\
\hline & Ginásio Nilson Nelson & & Documentário & & & $\mathrm{S} 15^{\circ} 46$ \\
\hline & \begin{tabular}{|l|} 
Concha Acústica do \\
Exercito \\
\end{tabular} & & Documentário & & & $\mathrm{S} 15^{\circ} 46^{\prime}$ \\
\hline & Catedral & & Documentário & & & $\mathrm{S} 15^{\circ} 47$ \\
\hline & Palácio Itamaraty & & Documentário & & & $\begin{array}{r}\mathrm{S} 15^{\circ} 48 \\
52^{\prime} 04.6^{\prime \prime}\end{array}$ \\
\hline & Hotel Nacional & & Documentário & & & $\mathrm{S} 15^{\circ} 47$ \\
\hline & Palácio Alvorada & & Documentário & & & $\mathrm{S} 15^{\circ} 47^{\prime}$ \\
\hline & Torre TV & & Documentário & & & $\begin{array}{l}\mathrm{S} 15^{\circ} 47 \\
53^{\prime} 30.4^{\prime \prime} \\
\end{array}$ \\
\hline & Teatro Nacional & & Documentário & & & \begin{tabular}{|l}
${\mathrm{S} 15^{\circ} 47}^{52.3^{\prime \prime}}$ \\
\end{tabular} \\
\hline \multirow[t]{3}{*}{ Além do Cinema } & Teatro Nacional & 1989 & Documentário & $\begin{array}{l}20 \\
\text { minutos }\end{array}$ & Pedro Anísio & $\begin{array}{l}\mathrm{S} 15^{\circ} 47 \\
52.3^{\prime \prime}\end{array}$ \\
\hline & Torre TV & & Documentário & & & $\begin{array}{r}\mathrm{S} 15^{\circ} 47 \\
53^{\prime} 30.4^{\prime \prime} \\
\end{array}$ \\
\hline & Vale do Amanhecer & & Documentário & & & $\begin{array}{r}\mathrm{S} 15^{\circ} 40 \\
39^{\prime} 14.51^{\prime \prime} \\
\end{array}$ \\
\hline \multirow[t]{7}{*}{ A capital dos Brasís } & Parque da Cidade & 1989 & Documentário & $\begin{array}{l}20 \\
\text { minutos }\end{array}$ & $\begin{array}{l}\text { Geraldo } \\
\text { Moraes }\end{array}$ & $\mathrm{S} 15^{\circ} 48^{\prime}:$ \\
\hline & Setor Comercial Sul & & Documentário & & & $\mathrm{S} 15^{\circ} 47^{\prime}$ \\
\hline & $\begin{array}{l}\text { Rodoviároa do Plano } \\
\text { Piloto }\end{array}$ & & Documentário & & & $\begin{array}{l}\text { S } 15^{\circ} 47 \\
59.0^{\prime \prime}\end{array}$ \\
\hline & Torre TV & & Documentário & & & $\begin{array}{l}\mathrm{S} 15^{\circ} 47 \\
53^{\prime} 30.4^{\prime \prime}\end{array}$ \\
\hline & Catedral & & Documentário & & & $\mathrm{S} 15^{\circ} 47$ \\
\hline & $\begin{array}{l}\text { Fonte de Água da Torre } \\
\text { TV }\end{array}$ & & Documentário & & & \begin{tabular}{|c}
$\mathrm{S} 15^{\circ} 47^{\prime}$ \\
$53^{\prime} 28.9^{\prime \prime}$ \\
\end{tabular} \\
\hline & Teatro Nacional & & Documentário & & & \begin{tabular}{|l}
${\mathrm{S} 15^{\circ} 47}^{52.3^{\prime \prime}}$ \\
\end{tabular} \\
\hline \multirow[t]{3}{*}{ Mínima Cidade } & $\begin{array}{l}\text { Páróquia Santa Cruz e St } \\
\text { Edwiges }\end{array}$ & 1984 & $\begin{array}{l}\text { Curta } \\
\text { metragem }\end{array}$ & $\begin{array}{l}8 \text { com } 26 \\
\text { minutos }\end{array}$ & João Lanari & $\begin{array}{r}\mathrm{S} 15^{\circ} 48^{\prime} \\
{ }^{\circ} 54^{\prime} 06.06^{\prime \prime}\end{array}$ \\
\hline & Casa quadra W3 sul & & $\begin{array}{l}\text { Curta } \\
\text { metragem }\end{array}$ & & & $\mathrm{S} 15^{\circ} 48^{\prime}$ \\
\hline & $\begin{array}{l}\text { Santuário Nossa Senhora } \\
\text { de Fátima } 906 \text { sul }\end{array}$ & & $\begin{array}{l}\text { Curta } \\
\text { metragem }\end{array}$ & & & $15^{\circ} 48^{\prime} 2$ \\
\hline
\end{tabular}




\begin{tabular}{|c|c|c|c|c|c|c|}
\hline & Quadra 912 sul & & $\begin{array}{l}\text { Curta } \\
\text { metragem }\end{array}$ & & & $15^{\circ} 48^{\prime} 5$ \\
\hline \multirow[t]{10}{*}{$\begin{array}{l}\text { Brasília, Um dia de } \\
\text { Fevereiro }\end{array}$} & Plataforma rodoviária & 1996 & Documentário & $\begin{array}{l}1 \text { hora e } \\
7 \\
\text { minutos }\end{array}$ & $\begin{array}{l}\text { Maria Agusta } \\
\text { Ramos }\end{array}$ & $\begin{array}{r}\mathrm{S} 15^{\circ} 47 \\
52^{\prime} 54.7^{\prime \prime}\end{array}$ \\
\hline & Congresso Nacional & & Documentário & & & $\begin{array}{r}\mathrm{S} 15^{\circ} 47 \\
47^{\circ} 52^{\prime} 01.1^{\prime \prime} \\
\end{array}$ \\
\hline & Pálacio Itamaraty & & Documentário & & & \begin{tabular}{|l}
$\mathrm{S} 15^{\circ} 48$ \\
$52^{\prime} 04.6^{\prime \prime}$
\end{tabular} \\
\hline & Catedral & & Documentário & & & $\mathrm{S} 15^{\circ} 47$ \\
\hline & $\begin{array}{l}\text { Parte inferior da } \\
\text { rodoviária do Plano piloto }\end{array}$ & & Documentário & & & $\begin{array}{r}\mathrm{S} 15^{\circ} 47 \\
52^{\prime} 55.2^{\prime \prime}\end{array}$ \\
\hline & $\begin{array}{l}\text { Escada Rodoviária do } \\
\text { Plano Piloto }\end{array}$ & & Documentário & & & $\begin{array}{l}\text { S } 15^{\circ} 47 \\
52^{\prime} 56.5^{\prime \prime}\end{array}$ \\
\hline & SCS 203\204 & & Documentário & & & $\begin{array}{r}\mathrm{S} 15^{\circ} 48^{\prime}: \\
47^{\circ} 53^{\prime} 22.77^{\prime \prime} \\
\end{array}$ \\
\hline & Icc norte Unb & & Documentário & & & \begin{tabular}{|l}
${\mathrm{S} 15^{\circ} 47}_{10.3^{\prime \prime}}$ \\
\end{tabular} \\
\hline & Torre TV & & Documentário & & & $\begin{array}{l}\mathrm{S} 15^{\circ} 47 \\
53^{\prime} 30.4^{\prime \prime} \\
\end{array}$ \\
\hline & Buraco do Tatu & & Documentário & & & $\mathrm{S} 15^{\circ} 47$ \\
\hline \multirow[t]{8}{*}{ Athos } & Hospital Sarah & 1998 & Documentário & $\begin{array}{l}20 \\
\text { minutos }\end{array}$ & \begin{tabular}{|l} 
Sergio \\
Muriconi
\end{tabular} & $\begin{array}{r}\mathrm{S} 15^{\circ} 47 \\
\mathrm{~W} 47^{\circ} 53^{\prime} 28.1\end{array}$ \\
\hline & Catedral & & Documentário & & & $\mathrm{S} 15^{\circ} 47$ \\
\hline & Congresso Nacional & & Documentário & & & $\begin{array}{r}\mathrm{S} 15^{\circ} 47 \\
47^{\circ} 52^{\prime} 01.1^{\prime \prime} \\
\end{array}$ \\
\hline & Teatro Nacional & & Documentário & & & \begin{tabular}{|l}
${\mathrm{S} 15^{\circ} 47}^{52.3^{\prime \prime}}$ \\
\end{tabular} \\
\hline & Igreja 307\308 sul & & Documentário & & & $\mathrm{S} 15^{\circ} 48$ \\
\hline & Pálácio Itamaraty & & Documentário & & & $\begin{array}{r}\mathrm{S} 15^{\circ} 48 \\
52^{\prime} 04.6^{\prime \prime}\end{array}$ \\
\hline & Atélier de Athos & & Documentário & & & $\begin{array}{r}\mathrm{S} 15^{\circ} 49 \\
47^{\circ} 55^{\prime} 11.10^{\prime} \\
\end{array}$ \\
\hline & Casa de Athos & & Documentário & & & $\begin{array}{r}515^{\circ} 49 \\
47^{\circ} 55^{\prime} 26.31 \\
\end{array}$ \\
\hline \multirow[t]{8}{*}{ Brasília ano 35} & Palácio Planalto & & Documentário & $\begin{array}{l}23 \\
\text { minutos }\end{array}$ & Waldir Pina & $\begin{array}{l}\mathrm{S} 15^{\circ} 47 \\
51^{\prime} 40.9^{\prime \prime}\end{array}$ \\
\hline & Catedral & & Documentário & & & $\mathrm{S} 15^{\circ} 47$ \\
\hline & Esplanada dos ministérios & & Documentário & & & \begin{tabular}{|}
$\mathrm{S} 15^{\circ} 47$ \\
$52^{\prime} 17.5^{\prime \prime}$ \\
\end{tabular} \\
\hline & Congresso Nacional & & Documentário & & & $\begin{array}{r}\mathrm{S} 15^{\circ} 47 \\
47^{\circ} 52^{\prime} 01.1^{\prime \prime} \\
\end{array}$ \\
\hline & Igreja 307\308 sul & & Documentário & & & $\mathrm{S} 15^{\circ} 48$ \\
\hline & Parque da Cidade & & Documentário & & & $\mathrm{S} 15^{\circ} 48^{\prime}$ \\
\hline & Rodoviária plano piloto & & Documentário & & & $\begin{array}{l}{\mathrm{S} 15^{\circ} 47}_{59.0^{\prime \prime}} \\
\end{array}$ \\
\hline & Torre TV & & Documentário & & & \begin{tabular}{|}
$\mathrm{S} 15^{\circ} 47$ \\
$53^{\prime} 30.4^{\prime \prime}$
\end{tabular} \\
\hline
\end{tabular}




\section{Chiclete da Rosa}

Bar beirute

Samambaia

Recanto das Emas

Santa Maria
13

minutos

e 30

2000 Documentário segundos Dacia Ibiapina

Documentário

Documentário

Documentário
S $15^{\circ} 49^{\prime}$

$\mathrm{S} 15^{\circ} 52^{\prime}$

$48^{\circ} 05^{\prime} 23.72$

$\mathrm{S} 15^{\circ} 54^{\prime}$ $48^{\circ} 03^{\prime} 54.85^{\prime \prime}$

$\mathrm{S} 16^{\circ} 00$ $47^{\circ} 59^{\prime} 19.77^{\prime \prime}$ 